\title{
ALCOHOL AND ILLICIT SUBSTANCE USE \\ IN THE FOOD SERVICE INDUSTRY: \\ ASSESSING SELF-SELECTION AND JOB-RELATED RISK FACTORS
}

\section{THESIS}

\author{
Presented in Partial Fulfillment of the Requirement for \\ the Degree Master of Science in the Graduate \\ School of The Ohio State University
}

By

Jinfei Zhu, M.S.

$* * * * *$

The Ohio State University

2008

Thesis Committee:

Professor Michael Tews, Advisor

Approved by

Professor Kathryn Stafford

Professor Thomas George

Adviser

College of Education and Human Ecology 


\begin{abstract}
Previously, most substance use research on workplace alcohol and drug problems have focused on four aspects: social control, norm, availability and stress. Due to the prevalence of substance use problem in the food service industry, this study investigates food service employee involvement with alcohol, marijuana, and other illicit drug using the National Longitudinal Survey of Youth 97 cohort. Self-selection is first examined using a multinomial logistic regression model. Then availability theory, norm theory, and stress theory are extended and tested by a number of job-related risk factors to predict employee substance use, using OLS models. Results show some evidence of selfselection: previous binge alcohol users and marijuana users had a greater likelihood to work in the food service industry. After controlling for previous substance use and individual backgrounds, bartending, tip earning, and holding multiple jobs were the major risk factors for employee alcohol or illicit drug use in the food service industry. Implications for practitioners are discussed and future research opportunities are then presented.
\end{abstract}


Dedicated to my parents 


\section{ACKNOWLEDGMENTS}

As I put the final touches on this thesis, it is my pleasure to thank the many people who have helped me through this journey.

First and foremost, I wish to thank my advisor, Michael J. Tews, for his support, insight and guidance; for his original research idea and excellent editing; and for his abundant trust on me to freely explore the topic to reach my goal. Over the past two years, Michael has been a great mentor and friend. Thank you for all the guidance on how to be an effective Teaching Assistant, and for setting a role model for professionalism in teaching.

I also wish to thank my co-advisor, Kathryn Stafford. I am deeply grateful for her consistent guidance, flexibility, as well as her expertise on the methodology. Dr. Stafford has been giving critical feedback on sample selection and analytical strategies. Her collaborative spirit and patient guidance were always helpful and timely. I appreciate the opportunity to work with you.

Also, I thank Thomas George, my co-advisor, for giving me valuable feedback on the thesis. Thank you for your counsel in helping me gain confidence in my abilities to finish this thesis. 
I give a debt of gratitude to my husband, Shane $\mathrm{D}$. Cline, who with a compassionate heart and brilliant mind gave countless hours to support me. Thank you for reading, amending, diagnosing, and questioning my study; passionately discussing and debating with me; and being with me throughout the journey. Your fantastic advice and encouragement are my biggest motivation to finish the thesis.

Finally I owe special thanks to my graduate fellows, especially Hua Zan and Franziska Schubert, for their friendship and consistent moral support throughout. 
VITA

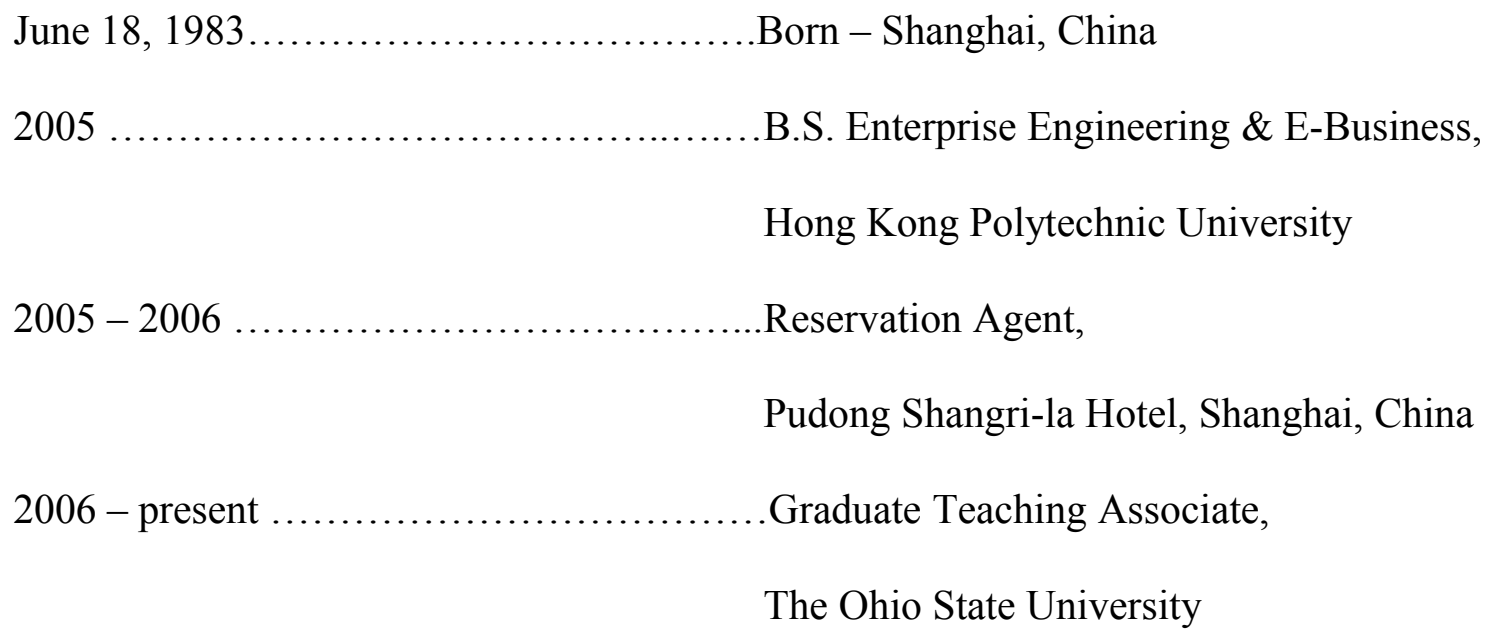

\section{PUBLICATION}

Research Publication

Tews, M.J., Stafford, K., \& Zhu, J. (under review). Beauty revisited: Examining the impact of attractiveness, ability, and personality in the assessment of employment suitability. International Journal of Selection and Assessment.

\section{FIELDS OF STUDY}

Major Field: Human Ecology

Hospitality Management

Minor Field: Statistical Data Analysis 


\section{TABLE OF CONTENTS}

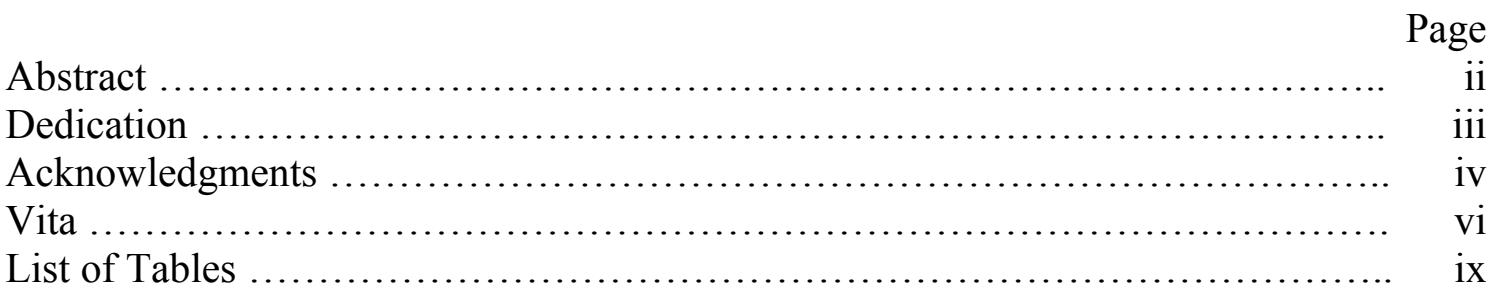

\section{Chapters:}

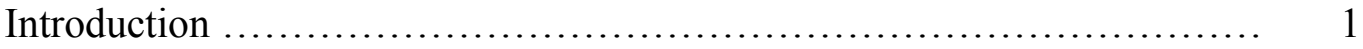

1. $\quad$ Literature Review ................................................... 8

Definitions of substance use ........................................... 9

Social control ................................................. 10

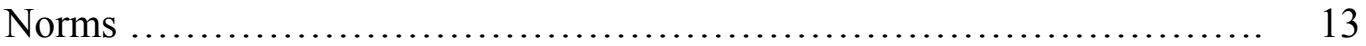

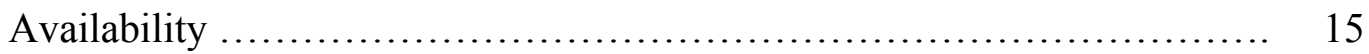

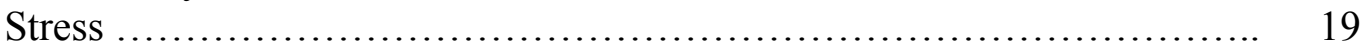

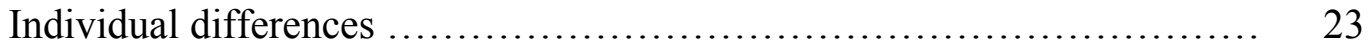

Summary and limitations of research in workplace substance use........... 26

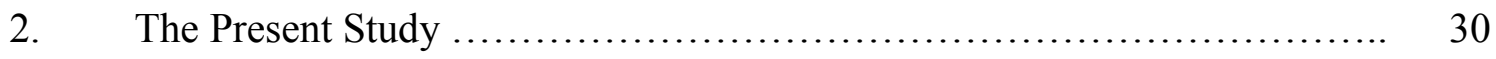

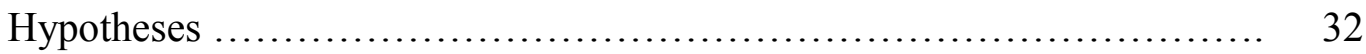

Self-selection ............................................... 32

Alcohol availability ........................................ 34

Cash resources ................................................ 34

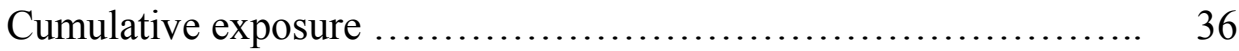

Norms for socializing ......................................... 37

Stress from multiple jobs ................................... 38

Methods ............................................................. 40

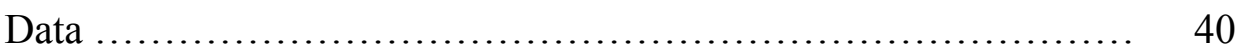

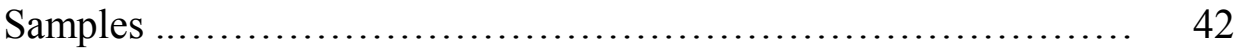

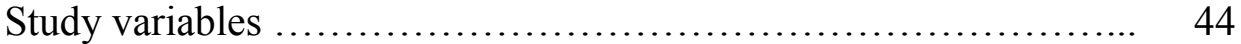

Analytical plan ............................................... 48

3. Results ............................................................... 56 
Self-selection hypothesis........................................... 56

Substance use hypotheses...................................... 59

Model significance ....................................................................... 62

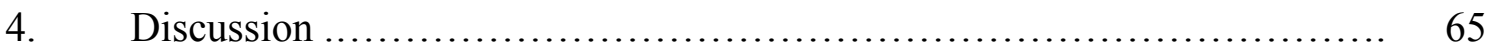

Discussion ................................................................................. 67

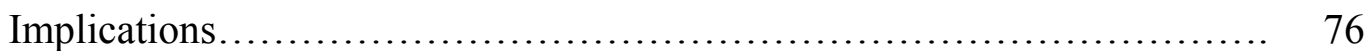

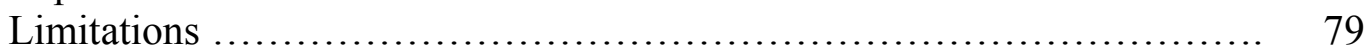

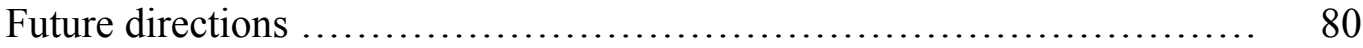

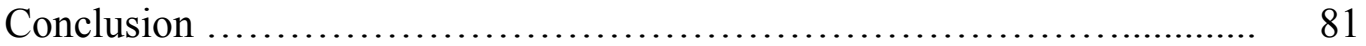

Appendix A Descriptive statistics of the self-selection sample break-down by food service, other high-use and low-use industries ....................................... 83

Appendix B Multinomial logistic regression results for self-selection into higher

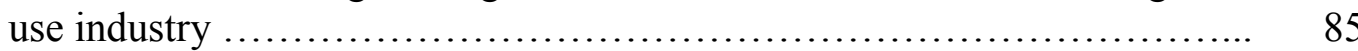

Appendix C F-tests for overall significance of job-related risk factors ................... 87

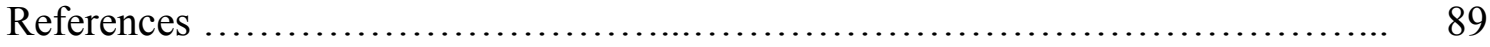




\section{LIST OF TABLES}

Table Page

2.1 Definitions of model variables ....................................... 52

2.2 Descriptive statistics of the self-selection sample......................... 54

2.3 Descriptive statistics of the food service worker sample .................. 55

3.1 Multinomial logistic regression coefficients and odds ratios for working in the food service industry ........................................ 58

3.2 OLS results of job-related risk factors for substance use in the food

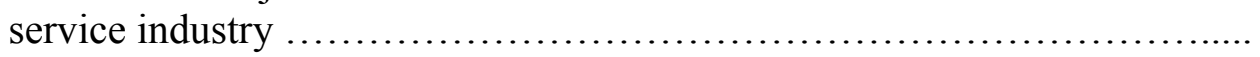




\section{INTRODUCTION}

There is a contemporary concern in America for understanding the prevalence

and causes of workers' licit and illicit drug uses. According to the Substance Abuse and Mental Health Services Administration (SAMHSA, 2007), a nation-wide survey conducted in 2006 revealed $62.0 \%$ of full-time workers reported drinking alcohol in the past month. It was also estimated that $29.7 \%$ and $8.9 \%$ of full-time workers engaged in binge drinking and heavy drinking respectively. In terms of current illicit drug use, the rates were $8.8 \%$ for full-time workers and $9.4 \%$ for part-time workers. Although substance use is generally more prevalent among unemployed persons compared with those from employment groups, most drug users were employed. For instance, the number of current illicit drug users in 2006 was equivalent to 13.4 million full-time or part-time employed people.

Substance use problems are especially prominent in the accommodation and food service industry. Combining data from 2002 to 2004, it was reported the accommodations and food services industry to have $16.9 \%$ of current illicit drug users among full-time workers aged 18 to $64^{1}$ and ranked highest among all industries (Larson, Eyerman, Foster, \& Gfroerer, 2007). Moreover, the accommodation and food services industry

${ }^{1}$ Data of part-time workers is unavailable. The accommodation and food service industry was combined into the entertainment and recreation industry when reporting part-time employee illicit drug use. 
had a $12.0 \%$ current heavy alcohol use rate and ranked fourth among all industries (Larson et al., 2007).

Within the accommodation and food service industry, the food service section has a greater problem with employee alcohol use and illicit drug use. More than $15 \%$ of food service employees were current heavy alcohol users, as compared to $10 \%$ in the accommodation section (Larson et al., 2007). Empirical studies in the food service industry provided more evidence to support the above epidemiological findings, particularly on alcohol use problems. It was found that higher alcohol use was associated with restaurant-affiliated employees rather than their accommodation counterparts (Larsen, 1994). The food service industry is considered to have a drinking culture (Corsun \& Young, 1998; Larsen, 1994; Stubbs, 2001), in which "alcohol is viewed favorably" (International Center for Alcohol Policy, 2003, p.5). Furthermore, the highest $(17.4 \%)$ ate of current illicit drug users (was found among food service employees, as compared to the accommodation and food service industry average (16.9\%) (Larson et al., 2007).

Due to its prevalence as discussed above, alcohol or illicit drug use is one of the most serious health problems affecting employers today. SAMHSA (2008a) estimates the medical cost and worker compensation related to the substance abuse problems to be more than $\$ 100$ billion a year, about twice as much as those of drug-free employees. It was further estimated that alcoholism being responsible for $40 \%$ of industrial fatalities and $47 \%$ of industrial injuries (Bernstein \& Mahoney, 1989). The cost of employee substance abuse is not limited to medical bills and wage replacement. Indirect drug using 
costs can include absenteeism, productivity loss, higher turnover, waste, theft, and property damage. Employee substance use also can cause damage to company reputation, employee morale, and increase legal liability for substance abuse problems caused by job stress (DiNardo, 1994). For small businesses in particular, one serious accident or one troubled employee can be devastating. For individuals, substance use can cause severe health consequences in addition to economic ones. More deaths, illness and disabilities are caused by substance use than any other preventable health condition (Brandeis University, 2001). According to the National Criminal Justice Reference Service, alcohol or illicit drug use is related to car accident, AIDS, birth defects, and a series of other health problem such as tuberculosis and hepatitis (National Criminal Justice Reference Service, 1997).

Above discussion demonstrates that substance use is a serious issue in the food service industry and thus research attention is warranted to understand what job characteristics are associated with employee substance use. There is a broad range of theoretical frameworks to explain an individual's alcohol or drug use decision in the general sense (e.g., Hogan, Gabrielsen, Luna, \& Grothaus, 2003; Szalay, Strohl, \& Doherty, 1999). One of the most popular models commonly used by drug prevention researchers is the risk and protective factor approach, which attempts to identify the risk factors and protective factors for individuals' involvement in substance use (Hogan et al., 2003). Risk factors are factors shown to increase the likelihood of employee substance use; whereas protective factors counter the risk factors, reducing the present of risk factors (Hogan et al., 2003). 
A number of individual or social-environmental and workplace risk factors for substance use have been identified. Individual risk factors include gender, age, peer or parental use, peer or parental approval of use, past delinquent behavior, academic achievement, and marital status. (see Hogan et al., 2003 for a review). In the workplace literature, four job-related risk factors for substance use have been most intensively studied. They are social control, permissive norms, substance availability and stress (see Harris, 2004 for a review).

However, previous empirical studies on these four workplace risk factors were constrained by the inclusion of limited sets of variables, limited industry focus, and the adoption of undependable research design. Consequently, past research has provided mixed findings and inconsistent conclusions. Some reviewers stressed drug involvement seemed more a function of individual qualities rather than workplace environment (Harris \& Heft, 1992; Herold \& Conlon, 1981). However, there is a logical relationship between working environment and individual's substance use behavior. The limitations of past workplace research may be the examination of limited sets of risk factors and the use of unsatisfactory research methods. In addition, limited research effort has been devoted to the food service industry, and those that focused on food service industry were often limited to alcohol use. Furthermore, selection bias is rarely recognized by past research in employee substance use, particularly among the food service studies.

In order to fill in the literature gap, the current study will extend previous research on job-related risk factors for substance use by first investigating self-selection into food service employment among previous users. Then a number of job characteristics specific 
to the food service industry will be examined using panel data from the National Longitudinal Survey of Youth 1997 (NLSY97) cohort. Consequently, the current research would differentiate itself and contribute to the literature in five aspects.

First, the current research examines self-selection, which is an alternative approach to understanding high substance use in the food service industry. Considering the strong drug use norm in the food service industry, it is necessary to assess whether the industry attracts predisposed individuals (Larsen, 1994; Plant, 1977). Most workplace substance use research has overlooked self-selection bias. The NLSY97 data enables this study to investigate how previous use of alcohol and illicit drugs impact on an individual's propensity to work in the food service industry. Therefore, this research will be the first study to assess self-selection into food service jobs in terms of employee substance use.

Second, this study extends availability, norm, and stress theory. It examines various food-service featured jobs characteristics including shifts, tip earning, and unique food service occupations such as bartenders and servers. The findings of this study will reveal the impacts of these food service job characteristics on employee involvement of alcohol, marijuana, and other illicit drugs.

Third, by using a nation-wide panel data, this study will be able to yield more generalizable conclusions and control for a wide range of individual variability. Compared to most past research, which often adopted unrepresentative samples, the present study gains generalibility from a nationwide sample. In addition, the extensive measures for individual characteristics and previous substance use enables the current 
research to control for the unobserved heterogeneity, which was frequently neglected by past works. Moreover, this study differentiate itself by the use of panel data to examine workplace impact on individual's substance use.

Furthermore, there is a strong industry focus of this study. As the food service industry has a large portion of heavy alcohol users and illicit drug users, it is imperative for researchers to understand the substance user profiles in this industry. This study will shed light on future research by proposing more industry-specific and occupation-specific risk factors for workplace substance use prevention. Due to the prevalence of substance use in the food service industry, this research will also provide significant managerial implications and suggestions for employees.

Last but not least, the current research will investigate a variety of substance use behaviors including alcohol, marijuana, and other illicit drugs. Because most previous studies have focused on employee drinking, illicit drug use is generally understudied. Given a high prevalence of illicit drug use in the food service industry, the current study will be able to provide insights to tackle both alcohol use and illicit drug use problems in this industry.

This thesis is comprised of four chapters. The first chapter provides an overview of previously identified workplace and individual risk factors for substance use. The literature review is summarized by a critique of limitations of the past research. The second chapter proposes a new framework to test and extend the norm and availability theory by examining specific job-related risk factors in the food service industry, with detailed theory-based induction and hypothesis to test. The second chapter is then 
followed by a description of the NLSY97 data, the current sample, key variables and the analytical strategies. The third chapter presents key sample descriptive statistics, and detailed hypothesis test results. The fourth, and final, chapter provides an interpretation of the results, addresses the implications of the current study, and presents opportunities for future research. 


\section{CHAPTER 1}

\section{LITERATURE REVIEW}

As discussed in the introduction, substance use in the food service industry is a prevalent problem. For the purpose of examining the nature of substance abuse in this industry, research attention is warranted to identify job-related factors that increase the risk of substance use. Substance use literature has primarily examined individual characteristics as the main predictors of substance use. But given the socialenvironmental perspective of drug addiction (Hogan et al., 2003), which attributes drug addiction to social-environmental factors, it is logical to assume that certain job-related features can also cultivate substance use.

A number of job-related risk factors have been examined in previous research to explain substance use at workplace. These factors can be subsumed into four general areas: social control, norms, availability, and stress. This chapter will review the previous research in these general areas along with research on individual characteristics and substance use. Since the focus of the study is to examine job-related risk factors for substance use in the setting of the food service industry, this chapter will also review the available substance use research specific to this industry. After a general review, this 
chapter will critique the literature based on the set of risk factors examined, the sampling methods adopted and the variables selected. The chapter will conclude with a general summary drawn from previous research, and will delineate opportunities for additional research attention.

\section{Definitions of Substance Use}

Before a review of literature, it may be necessary to clarify the definition of substance use adopted by this study. There are various ways to measure the levels of substance use. A very common method to categorize substance use by researchers as well as general public is substance use, misuse, abuse, and dependence. This four-level paradigm assesses substance use by the level of substance ingestion and the physical or psychological consequences of the ingestion.

The current study, however, borrows SAMHSA's definitions and will refer to substance use by "alcohol use", "marijuana use" or "other illicit drug use" throughout the thesis. The SAMHSA measurement is a behavioral scale using the frequency of ingestion to determine substance use. Alcohol use is measured differently from illicit drug use. The following paragraphs will specify the measurement in details.

Alcohol use is divided into four levels. Non-users of alcohol are defined as those individuals who report abstaining from alcohol use 30 days prior to survey. Current alcohol users refer to those who have used alcohol in the past 30 days. Binge alcohol use means "having 5 or more drinks on the same occasion on at least one day in the past 30 days". Finally, heavy alcohol use means "having 5 or more drinks on the same occasion 
on each of 5 or more days within the past 30 days".

To measure illicit drug use, SAMHSA takes a three-level approach: non-user, current user, and heavy user. Non-users of marijuana and other illicit drugs are those who have not used these drugs 30 days prior to survey. Current illicit drug use means at least one use of an illicit drug during the past 30 days. Heavy marijuana use has a different definition from heavy use of other illicit drugs. Specifically, heavy marijuana use is defined as using marijuana daily or almost daily in the past year (i.e., at least 300 days). Heavy use of other illicit drugs referred to using other illicit drugs (such as: cocaine, hallucinogens, heroin, inhalants, etc.) on at least 50 days in the past year, regardless of heavy marijuana use.

\section{Social Control}

The social control model of work-related substance use argues that social regulations in the workplace, both formal and informal, impact employees' risk of substance use (Trice \& Roman, 1972). The social control model is derived from managerial control theory, which lays down a foundation for understanding employee counterproductive behaviors and asserts that employees adopt counterproductive behaviors if they lack a clear understanding of managerial expectations. The social control model assumes that all aspects of social regulation at work, or its absence, can put individuals at high risk of substance use. Formal social control, or policy enforcement, consists of rules regarding substance use behaviors during work hours as written into an employee manual, labor agreement or other company media (Ames, Grube, \& Moore, 
2000). Formal policy also specifies treatment procedures as well as procedures for disciplinary action. On the other hand, informal social controls are "unwritten understandings about formal policy and about when the policy should or should not be enforced" (Ames et al., 2000, p.204) ${ }^{2}$.

Despite scattered research on the topic of workplace substance use sanctions, research has identified several job conditions that are linked with poor social regulation of workplace substance use. Trice and Roman (1972) argued such job conditions could be grouped into two categories: limited supervisory contact, and poor quality of supervision. Limited supervisory contact refers to overall weakened work structure (Parker \& Brody, 1982) such as: mobility during work hours (Trice \& Roman, 1972), working in isolation (Lehman, Farabee, Holcom, \& Simpson, 1995) and low visibility of worker (Parker \& Brody, 1982). Poor quality of supervision may happen when supervisors are unwilling to or incapable of taking an appropriate course of action (Harris \& Heft, 1992; Parker \& Brody, 1982).

One recent study that fully investigated the relationship between social control mechanisms at work and workplace drinking practice was conducted by Ames et al. (2000). They surveyed 1700 employees and conducted an ethnographic study with 110 employees in two large manufacturing plants within the same company located in the U.S. Social control was measured by formal and informal alcohol policy, disciplinary action, and the perceived likelihood of referral to an employee assistance program (EAP). The survey revealed alcohol policies and the extent to which the policies were enforced

${ }^{2}$ In fact, informal social control is similar to a norm, so "social control" can be viewed as policy enforcement and norms. 
predicted the drinking norms and alcohol availability at work.

In addition, Ames et al. (2000) were able to explore the relationship between organizational culture and social control and their impact on workplace drinking. The two plants worked on the same kind of products and were represented by the same union, but were managed by different managerial styles. One of the two plants had a traditional organizational culture characterized by visible symbols of status hierarchies, rigid division of job tasks, clear division between union and management, and a rigid decisionmaking process. The organizational culture in the other plant emphasized teamwork, empowerment and autonomy in decision making. The two managerial styles resulted in significant differences in employee drinking norms and drinking rates before and during work hours between the two plants. Specifically, the traditional organizational culture was associated with a more permissive drinking norm; whereas the non-traditional organizational culture was found to inhibit workplace drinking.

More recently, Bacharach, Bamberger and Sonnenstuhl (2002) used managerial control theory as the basis for their examination of the effect of policy enforcement on workplace drinking. Policy enforcement was measured by three indicators: contact with supervision, supervisor willingness, and ability to confront a troubled worker. With a self-report survey of 3400 unionized blue-collar workers, Bacharach et al. (2002) tested whether the impact of policy enforcement on problem drinking was mediated or moderated by norms, stress and alienation. Results were more complicated than expected. No significant mediating relationship was detected between policy enforcement and drinking Strong policy enforcement was found to offer limited utility 
in suppressing drinking problems. Nevertheless, Bacharach et al. (2002) found a

moderating effect of perceived norms between policy enforcement and drinking norms. The results are discussed in the following section.

Norms

Norms are collectively agreed, sanctioned prescriptions for, or prohibitions against, relevant others' behavior, belief, or feeling (Morris, 1956). Organizational norms are implicit rules that prescribe the ways in which all members of an organization should approach their work and interact with one another (Hammer, Saksvik, Nytroe, Torvatn \& Bayazit, 2004). The norm perspective of substance use, which is related to social learning theory, proposes substance using behavior is conditioned on a permissive highuse environment (Marlatt, 1985). According to Bandura's $(1973 ; 1977)$ social learning theory, people's learning behaviors are influenced by a combination of environmental (social) and psychological (cognitive) factors. Hence, substance use is a "bad habit" that is learned by observing important others or role models as to: how to do it, under which circumstances the behaviors are acceptable, and the possible results (Hogan et al., 2003, p.72; Szalay et al., 1999). If positive reinforcement is received after imitation of substance use behavior, it will then lead to the continuation of such behaviors. Positive reinforcement can be praise, acceptance, or inclusion for future substance-use activities (Szalay et al., 1999). It can also come in the form of an individual's psychological sense of being "just like" his or her role models. Negative reinforcement strengthens learning by avoidance of an aversive situation. 
A number of studies have examined the role of workplace norms as they affect substance use. Drinking norms have been consistently found to be the strongest predictor of work-related drinking (Ames \& Grube, 1999; Bacharach et al., 2002; Stubbs, 2001). Ames and Grube (1999) obtained data from three years of periodic onsite observations and semistructured interviews with 984 manufacturing workers, and found that perceived drinking by friends and co-workers was the strongest predictor of workplace drinking. Using a mediating model, Bacharach et al.(2002) were able to examine the relative importance of workplace substance use norms to predict substance use, compared with the other three workplace risk factors (stress, alienation and policy enforcement). Results indicated a perceived permissive norm was the most powerful predictor of workplace drinking, as compared to stress. Alienation and policy enforcement, however, were not found to statistically predict workplace drinking (Bacharach et al., 2002). To investigate the reasons for excess consumption of alcohol or drugs among bartenders, Stubbs (2001) carried out in-depth interviews with nine Canadian night-shift bartenders and found that in some bars managers and customers defined drinking while working as normative behavior for bartenders, and sharing a drink with customers was viewed as a bartender's obligation. In addition, all bartenders interviewed reported managers were flexible with their drinking policy, provided the bartenders did not become inebriated.

Ames et al. (2000) differentiated informal policy enforcement from norms, and referred to "drinking norm" as perceived approval/disapproval of drinking by various work team members. More specifically, workplace drinking was found to increase as perceived workplace drinking by others and perceived approval of drinking by others 
increased. The impact of social control on workplace drinking was mediated through norms, which in turn directly influenced worker's drinking behavior. In Ames et al.'s (2000) study discussed above, drinking norms accounted for the differences in drinking problems between the two plants.

Using the same measurement of drinking norms similar to Ames et al. (2000), Bacharach et al. (2002) found a moderating role of norms between substance use and policy enforcement. Three items measured permissive drinking norms by perceived coworker drinking amount (during lunch break, after work, and overall). Analysis revealed that under low or moderate drinking norms, increased policy enforcement had no significant association with problem drinking. On the other hand, under strong drinking norms, increased policy enforcement was found to be associated with higher levels of problem drinking. Bacharach et al. (2002) commented on the moderating effect of norms and stressed that strong policy enforcement was effective in reducing drinking problems when there were less permissive drinking norms; such managerial regulations might backfire, however, in a permissive drinking culture and result in more problematic behaviors. Bacharach et al.'s results were consistent with earlier studies of railroad workers (Mannello \& Seaman, 1979) and tunnel workers (Sonnenstuhl, 1996).

\section{Availability}

The availability theory assumes the use of a drug will be more prevalent and more severe if the drug is more available. According to availability theory, the easier it is to acquire a drug, the more that drug will be consumed in a given population (Saunders \& 
Aasland, 1987). The availability of a drug or the opportunity to use a drug is viewed as the prerequisite for drug involvement (Anthony \& Helzer, 1995; Ghodse, 1995). Prior epidemiology of drug dependence has investigated patterns in drug involvement among populations and has indicated that the relative availability of a drug (e.g., tobacco vs. cocaine) influences whether drug dependence has a chance to develop once drug use is initiated (Anthony \& Helzer, 1995). In the adolescent substance use literature, community substance availability is shown to increase the likelihood of adolescent substance abuse (Hogan et al., 2003). College students' participation in binge drinking was significantly higher when there were a greater number of outlets selling alcoholic beverage near campus (Chaloupka \& Wechsler, 2004). If perceived substance availability is high, regardless of the actual substance availability, it promotes substance consumption because the perceived availability supports a social norm of substance use (Hogan et al., 2003).

A few studies have used availability theory to analyze workplace substance use (Ames et al., 2000; Ames \& Grube, 1999; Frone, 2003; MacDonald, Wells \& Wild, 1999; Ramchand, 2006; Trinkoff, Storr \& Wall, 1999). Using data from the 1994 Nurses' Worklife and Health Study, a national survey of substance use among nurses, Trinkoff et al. (1999) examined the link between perceived availability and prescription-type substances in the workplace. Specifically, perceived availability was measured by the perceived ease of access to commonly administered controlled substances on three levels (easy, moderate, difficult). Results showed nurses with easy access were most likely to have misused prescription drugs. MacDonald et al. (1999) reported the perceived ease of 
obtaining drugs was positively related to drinking problems in a sample of employed adults. Ames and Grube (1999) interviewed 984 factory workers regarding their perceived ease of obtaining or consuming alcohol at work and revealed perceived physical availability of alcohol was not a significant predictor of work-related drinking when social availability, or drinking norms (Frone, 2003) was controlled. In a later study, Ames et al. (2000) measured perceived alcohol availability at work by asking respondents to indicate the degree of difficulty to obtain a drink at work, bring in a drink to work, consume a drink at a working station, and consume a drink during break. Perceived availability was found to positively correlate with work-related drinking. Availability of alcohol decreased as policy enforcement increased and as supervisor support for EAP increased. Finally, workers who drank more reported less alcohol availability at the workplace.

In the adolescent literature, working is found to be strongly related to youth substance use behaviors (e.g. Apel, Paternoster, Bushway, \& Brame, 2006; Paternoster, Bushway, Brame, \& Apel, 2003; Ramchand, 2006; Safron, Schulenberg, \& Bachman, 2001). The availability theory predicts that for youths working provides easier access to or more opportunity to use alcohol and illicit drugs. Ramchand (2006) used data from a longitudinal survey to assess the availability theory. Availability was measured from an "exposure opportunity" perspective. The measurement item asked youths their opportunities to use drugs and their ages of first opportunity to use drugs. Among youth who had not reported the opportunity for substance use through wave 9 , those who worked in both wave 10 and 11 reported significant increase in opportunity to use alcohol 
and tobacco compared to those who did not work in either period. Ramchand (2006) thus argued that working provided youths the chances to interact with adults who were substance users and were likely to introduce the youth to "adult-like" behaviors. Another adolescent substance use study (Carr, 1995) observed the same effect of work on youth substance use behavior and argued that working provided teens with incomes that can promote substance use behavior.

In the food service industry, where alcohol is "abundantly present" (International Center for Alcohol Policies, 2003), it is logical to assume the physical availability of alcohol facilitates employee drinking. Larsen (1994) provided direct evidence to the availability perspective on food service personnel's heavier drinking problems. He conducted a mail-in survey with 105 service workers from four types of service industries (restaurant, hotel and lodging, banking and insurance, and re-fuel stations) in Norway. Consistent with the availability hypothesis, results showed restaurant-affiliated employees scored significantly higher on the Alcohol Use Disorders Identification Test than other three service industries' workers. The higher physical availability of alcohol in restaurant may be the biggest factor in explaining the difference. Based on the finding, Larsen (1994) argued that the availability of alcohol was not limited to physical presence and proposed that psychological availability seemed to play a more important role among hotel and restaurant employees than in other service occupations.

Larsen's (1994) viewpoint coincides with Smart's (1980) conceptualization of alcohol availability, which, at the individual level, was comprised of subjective physical availability and social availability. The subjective physical availability is similar to what 
is now referred to as perceived availability (Hogan et al., 2003). The social availability was viewed as similar to drinking norms or peer approval of drinking (Ames \& Grube, 1999). Smart (1980) suggested these two availabilities may mediate and outweigh the actual physical availability.

On the whole, the availability theory has been moderately supported and perceived physical availability of alcohol at workplace predicts workplace drinking (Ames et al., 2000; Frone, 2003), but actual physical availability was not a consistent predictor of employee drinking (Ames et al, 2000; Frone, 2003; Larsen, 1994).

Stress

Consistent with the psychological model of addiction, which attributes substance addiction to the attempt to alleviate emotional pain caused by psychological problems (Hogan et al., 2003), the stress paradigm views work-related stress as a cause of employee substance use. Stress can be defined as "a demand made upon the adaptive capacities of the mind and the body" (Fontana, 1989, p.3), or a process by which "people perceive, interpret, respond, and adapt to harmful, threatening, or challenging events" (Ramchand, 2003, p.20). Job-induced stressors are the psycho-social demands at work that accompany the need to adapt to the work environment (Corsun \& Young, 1998) and can be categorized as those of physical environment (e.g. hazard, poor ergonomics), job content (e.g. workload, deadlines, overtime; job meaninglessness), organizational (e.g. job security, work group interaction; job autonomy), and extra-organizational (e.g. workfamily conflict) (Baker, 1985; Frone, 2003; Lehman \& Bennett, 2002). Strains are 
psychological and physiological responses to stressors. Psychological responses include feeling lack of job control, depression, job dissatisfaction and low organizational bonding (Lehman \& Bennett, 2002). Physiological responses include exhaustion, cardiovascular disease, poor health functioning, and sickness absenteeism (Kuper \& Marmot, 2003). Probably the largest body of literature on workplace substance use has focused on work-induced stress perspectives with drinking problems studied most extensively. However, empirical studies on the stress perspective have been equivocal. Some studies have found that work stress is directly or indirectly associated with workers' substance use (e.g., Conway, Vickers, Ward, \& Rahe, 1981; Head, Stansfeld, \& Siegrist, 2004). Conway et al. (1981) applied stress theory to the analysis of the use of multiple substances (tobacco, caffeine and alcohol) based on responses to a longitudinal survey of 34 men. Stress was measured by eight subjective stress items (including overall stress, anxiety, work load, and hours) and two mood items. Results indicated that habitual smoking and coffee drinking were positively associated with chronic tendencies to perceive high stress. However, no association was found between alcohol consumption and stress. Results also suggested that there were important individual differences associated with the results. Head et al. (2004) conducted a longitudinal study of London civil servants. Taking account of age and employment grade, analyses revealed that men's alcohol dependence was associated with effort-reward imbalance, after controlling for background heterogeneity. Among women, low decision latitude was linked to increased risk of alcohol dependence. However, Head et al. (2004) were unable to establish an association between high job demands and low work social support for men 
with alcohol dependence.

Other studies provided evidence against stress theory (e.g., Cooper, Russell \& Frone, 1990; Corsun \& Young, 1998; Frone, 2003; Wiesner, Windle, \& Freeman, 2005). With a random sample of 574 employed adults, Cooper et al. (1990) tested the tension reduction model, in which negative emotion plays a mediating role between stressors and alcohol-related behaviors. The results implied a need for more complex models. Of the three drinking outcome variables including drinking to cope, alcohol consumption, and drinking problems, none were predicted significantly by work-related stressors nor by negative emotions after controlling for socio demographic and psychosocial variables. Work stress was only found to interact with self-efficacy (referred as "mastery" by Cooper et al.) and was positively related with drinking to cope among individuals who had low self-efficacy. A more recent study by Wiesner and colleagues (2005) examined main and moderated relationships between five job stressors and substance use, using a community sample of 583 young adults. Analyses provided no statistical support for a direct association between job stress and binge drinking, alcohol consumption, and drug use. Corsun and Young (1998) surveyed 183 alumni of a hospitality program in the U.S. They hypothesized work stressors predicted work strains and both then predicted alcohol consumption. Stress was measured by stressors (e.g., role conflict, role ambiguity, etc.) and strain (e.g., work frustration, etc.). Results failed to support the hypothesis. Most stressors were unrelated to alcohol consumption. Interpersonal conflict, opportunity to deal with others, and all strain measurements were negatively correlated with alcohol consumption. Moreover, the study revealed that hospitality managers who made more 
income reported drinking more frequently. Based on the compelling evidence against stress theory, Corsun and Young (1998) argued that "significant negative correlations between three strain measurements and alcohol consumption indicate that alcohol may serve as a buffer between work stressors and strains" (p.205).

Theoretically, the stress-substance relationship is moderated by several other factors. Colder and Chassin (1992) argued alcohol consumption could be a functional behavior toward negative affective status, caused by stressful life events. Frone (1999) further demonstrated that the stress-alcohol link was moderated by coping behavior and by positive expectation for alcohol's effects. Individuals who lack proper coping mechanisms, combined with other contextual factors, may turn to substances to reduce tension. Sinha (2001) stressed that after repeated success, an individual may become dependent on substances to elevate mood and relieves stress. The stress-substance link was also found to be moderated by intrinsic job motivation (Wiesner et al., 2005), physical illness, and poor mental health (Head et al., 2004). A few studies investigated work-stress and actual substance use on the job and found on-the-job substance use was linked to: little faith in management, job dissatisfaction, high job tension (Greenberg \& Grunberg, 1995; Lehman \& Simpson, 1992) and high-risk on the job (Lehman et al., 1995).

The weak relationship between work stressors and employee substance use may be the result of researchers only examining a narrow representation of work stressors (i.e., most studies used workload and work control) (Newcomb, 1994; Frone, 1999) or the over-emphasis on alcohol-related problems (Frone, 1999). Interestingly, findings from 
hospitality managers provide significant evidence against stress theory (Corsun \& Young, 1998) and thus call for a new perspective on the relationship between work-stress and substance use in this industry.

\section{Individual differences}

As discussed above, past studies have attempted to establish job-related risk factors for substance use. However, several reviews (Harris, 2004; Hogan et al., 2003; Lehman et al., 1995; Newcomb, 1994) have indicated that the workplace has a limited relationship with employee substance use. Some studies found no relationship. When a relationship was found, it was often rather small. Therefore, it was argued that substance use was a function of individual characteristics. Hundreds of studies have been devoted to examining the correlations of general substance use. A number of individual or socialenvironmental risk factors have been consistently identified to be linked with substance use.

Age has a strong relationship with substance use. In the studies of adolescents, substance use increases with age, but peaks off as the users progress into adulthood (Anthony \& Arria, 1999; Lehman \& Simpson, 1992; Szalay et al., 1999). From a developmental standpoint, it is argued that substance use may be a normative behavior among young people and will decline in their mid-to-late 20s (Paglia \& Room, 1999). However, among adult hospitality managers, age was found to have a positive correlation with frequency of drinking (Corsun \& Young, 1998).

With regard to gender, males have been consistently shown to have more 
substance use problems than females, across age or ethnic groups (Frone, 2003; Lehman et al., 1995; Newcomb, 1994; Larson et al., 2007). Among hospitality managers, it was also found that men drank more frequently and engaged in heavy drinking more often than their female counterparts (Corsun \& Young, 1998). Using a sample of $319 \mathrm{New}$ York young workers, Frone (2003) reported higher rates of on-the-job use of both alcohol and marijuana by male workers than females.

The relationship between ethnicity and substance use is more complex. Generally speaking, Caucasians and Hispanic have similar usage rates, which are higher than both African Americans and Asians (Frone, 2003; O’Marrley, Johnston, \& Bachman, 1999;). Caucasians are more likely to report current use of alcohol (SAMHSA, 2008b). Among college students, Szalay et al. (1999) reported Caucasians had the highest level of vulnerability to substance use. There was also a higher rate of tobacco use among Caucasian youth aged 12 to 25 than other races of the same age group (Larson et al., 2007). In addition, American Indians or Alaska Natives reported more binge drinking, illicit drug use and current tobacco use as compared to other race groups (Larson et al., 2007). Among working youth, minorities were less involved with substance use, as compared with Caucasians (Johnson, 2004).

Marriage is consistently identified as a protective factor for substance use. In particular, married individuals often have fewer substance use problems than unmarried ones. Cross-sectional studies have generally confirmed a positive association between alcohol or illicit drug use and not being married (Cahalan \& Cisin, 1976; Heien \& Pompelli, 1987; Linsky, Straus, \& Colby, 1985). Since unmarried people tend to be 
younger, an NHSDA study used direct age standardization to adjust for different age distributions. Results confirmed that among full-time workers aged 18 to 49 , married ones were less likely to be heavy alcohol users and current illicit drug users than those who were unmarried (Hoffman, Brittingham, \& Larison, 1996)..

In addition, educational status or academic competence is related to substance use. Current alcohol use increases with the level of education. Specifically, $67.4 \%$ of college graduates were current drinkers, while $37.8 \%$ of adults with less than a high school education were current drinkers. However, binge or heavy use of alcohol is less prevalent among college graduates (Hermos, Winter, \& Heeren, 2008). With regard to illicit drug use, education levels were inversely correlated with illicit drug use (Hermos et al., 2008). The rate of current illicit drug users among college graduates (5.8\%) were considerably lower compared with those who did not graduate from high school (9.1\%) or high school graduates (8.0\%). Moreover, Szalay et al. (1999) reported college students who skipped more classes and reported lower GPA were more vulnerable to substance use.

Moreover, among the adolescent literature, association with drug-using peers has been found to be one of the strongest predictors of adolescent substance use (e.g., Akers, 1977; Elliott, Huizinga, \& Ageton, 1982; Foster, 1984; Spooner, 1999). On one hand, adolescents who reported substance use are also those who self-select to be friends with alcohol or drug-using peers, and spent less time with parents or structured extracurriculum activities (e.g., Barnes, 1977, Auerswald, 1980; Jessor, Chase, \& Donavan, 1980). On the other hand, affiliation with substance using peers can increase opportunity 
to use and social pressure to use, thus increases youth's risk of initiation of use (e.g., Kandel, Kessler, \& Margolies, 1978; Jessor et al., 1980; Petraitis, Flay, \& Miller, 1995; Shilts, 1991).

Past research on the impact of socioeconomic status (SES) or family income, however, has not identified SES has a consistent predictor for substance use. It has been shown that the association between SES and youth substance use were moderated by other individual characteristics such as race or depressive symptoms (Goodman \& Huang, 2002). Moreover, once community characteristics such as drug availability were controlled for, income had no effect on youth drug use (Maddahian, Newcomb, \& Bentler 1986). However, in the workplace literature, light to moderate use of alcohol has been shown to increase one's job outcome such as income (Peters, 2002). This is particularly true in the accommodation and food service industry (Corsun \& Young, 1998).

\section{Summary and Limitations of Research in Workplace Substance Use}

Past research on workplace substance use has mainly focused on four perspectives: norms, social control, availability, and stress. The general findings of these perspectives can be summarized in five points. One, norms have been demonstrated to be the best predictor of perceived alcohol availability, workplace drinking and overall marijuana use (e.g., Ames et al., 2000; Frone, 2003). Two, the role of social control is conditioned on norms whereby social control is more effective in controlling substance use when norms are weak (e.g., Bacharach et al., 2002). Three, perceived availability of alcohol in the workplace predicts workplace drinking (e.g., Ames et al., 2000; Frone, 
2003). Four, the impact of workplace stress on substance use is inconsistent and mixed. Five, several review studies argued that job-related risk factors generally have limited and mixed effects on employee substance use, which seems more of a function of individual characteristics (Harris, 2004; Harris \& Heft, 1992; Herold \& Conlon, 1981; Hogan et al., 2003; Lehman et al., 1995; Newcomb, 1994).

A close examination of previous literature suggests that the weak relationship found between work and substance use may be a result of several major limitations. First, past studies have only examined a limited set of risk and protective factors, particularly within the food service industry. Second, the dependent variable has often been limited to alcohol use only, with a few exceptions that used multiple substance use outcome in one investigation. Third, previous research designs were unoptimized. These limitations will be discussed in detail in the rest of this chapter.

The first limitation of past research is that the variables examined were often quite incomprehensive (Frone, 2003; Mensch \& Kandel, 1988; Newcomb, 1994). Many workplace studies have overlooked non-workplace factors such as individual differences and broader environmental factors in their models. For example, some studies (e.g., Corsun \& Young, 1998; Larsen, 1994) only investigated workplace factors, whereas in adolescent substance use studies, the only workplace characteristics examined repeatedly is work intensity (working hours per week). A review by Newcomb (1994) concluded drug use at work was not highly related to many work-related variables. Newcomb (1994) stressed "drug use in the workplace appears to be more a function of the individual and his or her personal qualities rather than his or her environment, regardless 
of whether the environment is defined as at work or home (p.48)". However, work environment, particularly occupational-specific ones, should not be ruled out as a contributing or intervening factor for substance use. Therefore, researchers (e.g. Lehman et al., 1995; Ramchand, 2003; Stubbs, 2001) are calling for closer attention and a detailed investigation of specific job characteristics in order to fully understand the risk factors at work. This said, not only should one take full consideration of individual propensity to drug use, but must also carefully select job-specific characteristics so as to capture the impact of work on employee substance use.

Second, previous workplace studies have over-emphasized alcohol consumption and left the other types of drugs almost unstudied (e.g., Ames et al., 2000; Corsun \& Young, 1998, Larsen, 1994). Only a few studies have used multiple substance use outcomes in one investigation (e.g., Frone, 2003; Lehman \& Bennett, 2002; Mensch \& Kandel, 1988). Theoretically, further research attention is needed to understand illicit drug use. Practically, employees' involvements in illicit drug use may impair memory, attention and decision making (Coambs \& McAndrews, 1994). Thus it is of practical significance to extend our understanding beyond alcohol use.

Last, research design of previous research has not been always optimal. Most workplace literature conducted one survey at one point in time and used cross-sectional data to explain the associations between working and substance use. Only one empirical study (Head et al., 2004) was found to use longitudinal data to trace the effect of stress on substance use. However, the sample (consisting of 33 men) was small and unrepresentative. In addition, the samples used in past studies were usually not 
representative of the population of interest. They were often too small, from one company or one hospitality management college (e.g., Corsun \& Young, 1998), or limited to one occupation (e.g., Trinkoff et al., 1999). Therefore, problematic sampling method constrained the ability of previous studies to generalize their findings. 


\section{CHAPTER 2}

\section{THE PRESENT STUDY}

As discussed in the previous chapter, past research on workplace substance use has mainly focused on four perspectives: norms, social control, availability and stress. The general findings of these perspectives are as follows. Norms have been demonstrated to be the best predictor of workplace drinking and overall marijuana use (e.g., Ames et al., 2000; Frone, 2003). The role of social control is conditioned on norms whereby social control is more effective in controlling substance use when norms are weak (e.g., Bacharach et al., 2002). Perceived availability of alcohol in the workplace predicts workplace drinking (e.g., Ames et al., 2000). Finally, the impact of workplace stress on substance use is inconsistent and mixed.

On the whole, previous research has advanced our understanding of specific risk and protective factors that impact work-related alcohol and illicit drug use. However, some limitations should be noted, which the present study strives to address. One, previous research has only examined a limited set of risk and protective factors, particularly within food service contexts. Two, the dependent variable has often been limited to alcohol use only. Three, the research designs employed have not always been 
optimal. To help address these issues and extend previous substance use research, the present study will examine the impact of risk and protective factors that have not been previously studied on multiple substance use outcomes with a national dataset of employee.

To bridge the gap in literature, this research attempts to investigate the prevalent substance use problem in the food service industry by examining self-selection and several job-related risk factors. Self-selection is one possible explanation for alcohol or drug use among food service employees but has never been addressed before by other workplace substance use studies. The current study will also extend norms, availability, and stress theory to further examine some special characteristics of food service jobs, such as earning tips, working an evening shift, holding multiple jobs and their relationships with employees' engagements with alcohol, marijuana, and other illicit drugs.

The present study will use the NLSY 97 cohort, which is designed to be representative of people living in the United States in 1997 aged 12 to 16. The NLSY97 sample includes nearly 9,000 individuals and collects extensive information annually on these young people's labor market behavior and substance use behavior. The longitudinal data will aid in determining young adults' experience related to employment and involvement in substance use.

The following sections of this chapter consist of a number of theory-based hypotheses and detailed descriptions of the methods used to test them. Specifically, the study proposes six hypotheses including self-selection, alcohol availability, cash 
resources, cumulative exposure, norms for socializing and job-related stress. The method section will present a detailed discussion of the data, the sample selection, explanatory and controlled variables, and the analytical plan.

\section{Hypotheses}

\section{Self-selection}

Considering the prevalence of alcohol and drug use problems in the food service industry, it is hypothesized that there may be a self-selection effect, i.e., people with substance use history will be more likely to self-select into the food service industry. The theoretical basis for this hypothesis is the attraction-selection-attrition (ASA) model (Schneider, 1987). The ASA model argues that one's vocational choice is a function of his or her own interests and personality. In other words, people tend to prefer working with others who are similar to them. Therefore, the prevailing alcohol and illicit drug use norms in the food service industry may be appealing to substance users during jobhunting.

The self-selection hypothesis assumes an addictive effect of substance use. Addiction is a compulsion and a craving to use alcohol or other drugs regardless of negative or adverse consequences (Hogan et al., 2003). As a drug is ingested, it eventually reaches the central nervous system and disrupts the messages sent to and from the brain. Major addictive effects of alcohol are muscle relaxation and anxiety reduction. Marijuana can increase appetite and cocaine can elevate mood (for a review of the main addictive effect of drugs, see Hogan et al., 2003, p.92-96). Depending on the type of 
drug and amount of consumption, withdrawal after addiction can cause psychological or physical discomfort such as sweating, tremors, drug craving, depression, lethargy, irritability, loss of concentration, etc. (Hogan et al., 2003, p.69). Therefore, substance use can be hard to withdraw from and may persist over time. Studies have shown that past involvement in substance use has been found to be one of the strongest predictors for the substance use one or two years apart (e.g., Boys et al., 2002; Stacy, Newcomb \& Bentler, 1992; Teichman, Barnea, \& Ravav, 1989). With this said, the addictive nature of alcohol and illicit drug use may drive an individual to work for a permissive work environment, where substance use is normative.

However, using workplace risk factors to predict employee substance use has been a common approach taken by past research, and no study has investigated employees' substance use behaviors prior to employment and its impact on employment. Larsen (1994) revealed higher alcohol use in restaurant-affiliated service employees and anticipated self-selection to be one explanation for the heavy drinking norm in the food service industry. The NLSY97 data enable the present study to examine how previous substance use may affect employment choice, i.e., self-selection into high use industries.

Since the food service industry had the highest percentage of employees reporting current illicit drug use (Larson et al., 2007), the self-selection hypothesis test whether heavy illicit drug users are more attracted to the food service industry. The alcohol use, construction, mining, and the arts and entertainment industry were the three industries that had a higher proportion of heavy alcohol users than food service industry (Larson et al., 2007). Therefore, the self-selection hypothesis proposes heavier alcohol users to self- 
select into food service industry, or construction, mining and arts and entertainment industry.

To summarize the above discussion, it is hypothesized that:

H1: When holding previous employment constant, the level of previous alcohol or illicit drug use is positively correlated with an individual's likelihood to work for the food service industry.

\section{Alcohol Availability}

Certain food service occupations, especially bartenders, are expected to be involved in more alcohol use based on availability theory. According to availability theory, a particular drug will be consumed more if that drug is perceived as more available. It has been previously found that nurses who have access to prescription-type substances were more likely to misuse those substances (Trinkoff et al., 1999). Similarly, bartenders' daily job duties involve direct handling of alcohol and thus have high

proximal availability of alcohol at the workplace. Based on the tenants of availability theory, the following hypothesis is proposed:

H2: Bartenders will engage in more alcohol use than other occupations within the food service industry.

\section{Cash Resources}

Food service employees who receive tips as a regular part of their compensation are hypothesized to engage in greater substance use. This hypothesis is based on the 
assertion that employees who receive tips possess the financial resources to more readily purchase alcohol and illicit drugs. There is evidence of a surge of substance use around the beginning of the month, when income checks are typically received (Shaner et al., 1995; Wallace, 1989). Interviews with cocaine addicts suggested that the receipt of money may lead to recurrent cocaine use (Wallace, 1989). A study of Schizophrenic cocaine abusers showed cocaine use peaked shortly after the arrival of disability payments (Shaner et al., 1995). Therefore, money management may be a key to influence alcohol or illicit drug use behavior (Rosen, Bailey \& Rosenheck, 2003).

Unlike many other industries, the food service industry provides employees with opportunities to earn a gratuity. The total amount of tips is estimated to be more than $\$ 20$ billion a year and makes up a considerable income source for the nation's two million servers (Lynn, 2006). Because almost all of servers' base income is consumed by tax deduction, tips become the primary take-home income for the servers (Lynn, 2006). In the food service industry, tip earnings are commonly distributed to employees in cash at the end of each shift. Therefore, the employees leave work with cash in their pockets.

No past research has investigated the relationship between tips and substance use. However, this study hypothesizes earning tips is a risk factor for employee substance use based on evidence from economic studies of consumer self-control. It has consistently been found that the propensity to spend is greater when an individual holds cash (Fudenberg \& Levine, 2006; Huffman \& Barenstein, 2005), and the propensity to spend cash is especially great when an individual's economic resources are low (Deaton, 1992; Vohs \& Faber, 2007), as is the case for many food service workers. Since tips are usually 
paid to the employees at the end of the day in cash, the impulse to spend that money should be strong. Moreover, it has been reported that when purchasing a good for immediate enjoyment such as alcohol or drugs, an individual is more likely to pay by cash, because cash is more anonymous than credit cards, debit cards or checks (Wertenbroch, Soman \& Nunes, 2002). Furthermore, if the amount of cash in pocket is sufficiently small, it is likely to be spent entirely (Fudenberg \& Levine, 2006).

Based on the above discussion, it is hypothesized that:

H3: Food service employees who earn tips will engage in more substance use.

\section{Cumulative Exposure}

It is further hypothesized that cumulative exposure to such a norm in the food service industry would increase an individual's involvement with alcohol or illicit drugs based on the tenants of norm theory. The above literature review of norm theory indicates a permissive norm, measured by perceived peer substance use or perceived supervisor approval of substance use, is the best predictor of substance use. Several empirical studies found a strong permissive drinking norm in the hospitality industry, where alcohol functioned as a social lubricant (Stubbs, 2001; Corsun \& Young, 1998; Peters, 2002). There is also qualitative evidence indicating new bartenders socialize into their job roles by excessive drinking (Stubbs, 2001). In addition to a drinking norm, the proportion of current illicit drug users among food service workers was found to be the highest among all industry groups (Larson et al., 2006). Based on the norm perspective and social learning theory, an individual is more likely to observe and imitate coworkers' 
substance use behavior if he or she is exposed to a high substance use norm in the work environment. Moreover, the ASA model suggests while some people may be attracted to the food service industry because of the drinking or illicit drug use norms, others may find themselves a poor match for the work environment and thus leave the industry (Schneider, 1987). Since socialization is a gradual process, an individual will adopt normative behaviors when exposed to such norms or self-select out of the job. Therefore, it is hypothesized that:

H4: Substance use among food service employees is positively associated with their cumulative work experience in the food service industry.

\section{Norms for Socializing}

The shifts food service employees work may impact their substance use. Specifically, those who work an evening shift are argued to more likely engage in substance use. This argument is based on the norms for socializing. Parties or social gatherings are commonly related to substance use (especially drinking and marijuana use) among young people. A survey of college students revealed user images of alcohol were associated with parties, fun and friends (Szalay et al., 1999). Empirical studies found that alcohol use among youths primarily occurs during Friday and Saturday night social gatherings (Larsen, 1984). With regard to illicit drugs, user images are high and fun (Szalay et al., 1999). Although daily users often use alone, social users are brought out by night time social gatherings. It was found that illicit drug use among young adults usually takes place at late night social activities with friends (Suchman, 1967). 
The evening shift is one essential feature of food service jobs and can be related to the socializing culture of substance users. Because dinner is the busiest time for the industry, working an evening shift is very common among food service employees. Upon finishing the evening shift, the employees' options to relax and socialize are generally limited to bars or night clubs, both of which are associated with drinking and drug using, and vice versa.

Few studies have examined the impact of work schedule on employee substance use. A study with nurses revealed working a night shift for more than eight hours increases nurses' likelihood of alcohol use (Trinkoff \& Storr, 1998). As the authors pointed out, one explanation for this finding is that night shift provides access and opportunities for substance use. Similarly, in the food service industry, working the evening shift may facilitate alcohol and illicit drug use, particularly in a social use manner. Therefore, working the evening shift may be associated with increased opportunities for social gathering, and thus be linked indirectly to the availability of alcohol and drugs. It is formally hypothesized that:

H5: Individuals who work an evening shift will be engaged in more substance use.

\section{Stress from Multiple Jobs}

Last but not least, holding multiple jobs is hypothesized to be a risk factor for substance use among food service employees, as derived from stress theory. According to stress theory, individuals may turn to alcohol or drugs as a means to relieve stress and 
improve mood. Stress has been measured in various ways as discussed in the literature review. But no past research has used multiple-job holding as a stress measure to examine its association with employee substance use. The current hypothesizes that because of role overload, multiple job holding to be a type of job-related stressor that increases employee substance use. A role is the expected behaviors assumed by the others in a given setting (Barling, Kelloway, Frone, 2004). Role overload is usually defined as a person's inability to fulfill various organizational expectations in the time available, or given the qualifications one has (Beehr, 1985; French \& Caplan, 1973). A large body of literature has concluded that role overload would induce stress and exert a negative effect on psychological well-being (e.g., Barnett \& Baruch, 1985; Goode, 1960; $\mathrm{Lu}, 2008$ ). Multiple job-holding also has been found to increase stress, reduce job satisfaction and suppress well-being (e.g., Burden, 1986; Muhammad, Baba, Riviere, 1998). Besides role overload, holding multiple jobs directly increases one's working hours. There have been evidences that number of working hours per week, or work intensity, was highly correlated with adolescent substance use (e.g., Carr, 1995, Johnson, 2004; Ramchand, 2003; Safron et al., 2001). Although the adolescent literature did not link work intensity with stress, it is possible that work intensity was, in fact, correlated with number of job and affected on adolescent substance use via stress. Given this said, it is logical to assume as one holds more jobs, he or she would experience more stress, and would be more likely to use alcohol or illicit drugs, according to stress theory.

The food service industry is a major source of part-time jobs for young people. Nearly $52 \%$ of young adults aged under 25 and $40 \%$ of food service employees work part 
time to earn extra money (BLS, 2007). Because these young workers are often highschool or college students who work while studying, balancing the roles of student and worker can be challenging. Moreover, earnings in the food service industry is typically much lower than the average for all industries, i.e., $\$ 8.69 /$ hour as compare to $\$ 16.76 /$ hour (BLS, 2007). Therefore, one may need to work more jobs to make extra money. Hence, using number of jobs held as a proxy for stress, it is hypothesized:

H6: Individuals with more jobs will engage in more substance use.

\section{Methods}

\section{Data}

The present study employs the NLSY97 cohort, which is a newer survey of the National Longitudinal Survey (NLS) program conducted by the Bureau of Labor Statistics (BLS) under the U.S. Department of Labor (NLS, 2007). The NLSY97 sampled people who resided in U.S. in 1997 and were born between January 1, 1980 and December 31,1984 . It is primarily designed to represent today's youths' transition from school to the labor market so it contains detailed information on youths' education and workforce experience. In addition, the survey also contains an extensive selfadministrated portion on youth substance use behavior. The first round of the survey was conducted in 1997 and a total of 8,984 individuals were surveyed. To date, BLS has released nine rounds (1997 to 2005) of data on the NLSY97 cohort. The NLSY97 cohort has maintained a fairly high retention rate, $81.7 \%$.

In addition to a greater generalizability from the national sample, the NLSY97 
cohort is well designed for this study because the focus of the current study is the food service industry, which employs a large number of young adults. In 2006, 43\% of workers employed by the food service industry were between the age of 16 and 24 (BLS, 2007). Thus the NLSY97 cohort is a sample of people who comprise nearly half of the food service industry employees. Moreover, illicit drug use, especially marijuana use, is more prevalent among young people, as discussed in the literature review. Therefore the information about youth substance use in the NLSY97 cohort may reflect a substantial portion of the substance use in the food service industry.

The NLSY97 cohort is comprised of two independent probability samples: a cross-sectional sample of 6,748 respondents and an oversample of 2,236 Hispanic/Latino and African Americans. The NLSY97 cohort was selected in two phases. The first phase selected households for screening, using stratified multistage area probability sampling. In the second phase, eligible respondents who were born between 1980 and 1984 were identified.

Interviews were conducted using a computer-assisted personal interview (CAPI) instrument, administrated by an interviewer on a laptop computer. During the in-person interview, sensitive questions such as substance use were directly entered by the respondent into the laptop computer. When an in-person interview could not be conducted, a phone interview was used instead and respondents had to answer sensitive questions directly. 


\section{Samples}

This research will use employed individuals from round six of the NLSY97, collected in 2002. This round of data was used to balance competing interests. It was desirable to maximize the number of individuals employed within the food service industry, while using recent data from the NLSY97. Round four had the maximum number of respondents employed in the food service industry, but round nine was the most recent data available. However, round nine had approximately fifty percent fewer individuals employed in food service than in round four. It was also desirable to use a sample in which individuals had greater occupational choice. At age 18, individuals are no longer minors and, therefore, legal restrictions on employment are fewer regarding alcohol service and working hours (Fair Labor Standard Acts, 2008; Hanson, 2005). Based on these interests, the decision was made to use data from round six, in which all respondents were at least 18 years of age, the data were collected within the last ten years, and where approximately fifty percent more individuals were employed in food service than in round nine. Round six included 5,060 employed individuals, 822 of whom were employed in the food service industry, and 312 were employed in other high use industries.

The employed individuals were on average 20.11 years old, and 50.18 percent of the sample was male. The ethnic background of the employed sample was as follows: 63.96 percent Caucasian, 21.40 percent African Americans, 7.50 percent Hispanic/Latino, 1.94 percent Asian/Pacific Islander, 0.61 percent Native American, and 4.59 percent "others." Table 2.2 provides a detailed sample description. For a break- 
down of sample statistics of the three industry subsamples, please refer to Appendix A. A special note should be taken that with an average age of 20 , a substantial portion of the sample were under the legal drinking age.

Although most of respondents $(87.17 \%)$ in this working sample held one job during the time of the interview, having two or more jobs was not uncommon $(12.83 \%)$. One "main" job needs to be decided so that industry and other job's characteristics can be used to test the hypotheses. However, when a respondent held multiple jobs at the same time, the NLSY97 questionnaire does not contain a systematic mechanism for sorting job numbers and respondents are not asked which the "main" employer is. Therefore, the current study draws upon the number of hours worked per week as the main criteria for the "main" job. If information on working hour is unavailable, then total tenure with each current employer is used as the secondary criteria. Thus, each individual in the sample is assigned one "main" job. The job characteristics associated with that main job are to be examined.

Based on the main job, the final sample size was reduced from 5060 working individuals to 822 individuals whose primary present job was in the food service industry during the 2002 interview. Food service industry is defined by the 2002 Census industry code 8680 (restaurants and other food services) and 8690 (drinking places, alcoholic beverages). Table 2.3 contains a detailed sample description for the food service sample.

Food service employees were on average 19.77 years old, and 44.98 percent were male. The ethnic composition of food service employees was 60.01 percent Caucasian, 21.85 percent African Americans, 10.31 percent Hispanic/Latino, 1.75 percent 
Asian/Pacific Islander, 1.18 percent Native American and 3.90 percent "others."

\section{Study Variables}

Three types of variables are used for the current study: substance use variables, job-related explanatory variables, and control variables. The following section will describe each variable in detail. Table 2.1 lists the definitions or measurement for all the variables. Table 2.2 and 2.3 summarize descriptive statistics for the modeled variables.

\section{Substance Use}

Alcohol use: Measurement of alcohol use focuses on the frequency of alcoholic beverage consumption in the past 30 days. An alcoholic beverage was defined as "a can or bottle of beer, a glass of wine, a mixed drink, or a shot of liquor" (NLS, 2007). The NLSY97 questionnaire contained three alcohol use questions. Respondents were asked the number of days they had one or more alcoholic beverage(s) in the past 30 days, the number of days they had five or more alcoholic beverage(s), and the average number of alcohol beverage(s) he or she had on the drinking days.

Marijuana use: Marijuana was also referred to as "grass" or "pot" in the questionnaire. Youth's level of marijuana use was measured by the number of days that youth had smoked marijuana in the 30 days prior to the interview.

Other illicit drug use: In addition to marijuana use, youths were asked about their use of any illicit drugs such as cocaine, crack, heroin, or any other substance not prescribed by a doctor in order to get high or to achieve an altered state. Other illicit drug use was measured in a one-year time frame. Respondents were asked the number of 
times they took a drug or other substance since the last interview.

\section{Job-related Explanatory Variables}

Occupation: Since occupation is mainly used to test alcohol availability, various food service occupations are categorized into four groups, according to their proximity of alcohol at work. Specifically, based on the Census 2002 occupation code, food service jobs are divided into: bartenders, servers, back-of-the-house workers (including cooks, food preparation workers, and dishwashers), and all others (including cashiers, hosts and counter-attendants, combined food preparations and serving workers, receptionists, janitors, securities, and managerial workers). The occupation variables are indicator variables, with all others being the reference group.

Tips: NLSY97 cohort contains information on the types of compensation youth received from work and the hourly compensation. A tip is one of the compensation types in NLSY97. An indicator variable for tips denotes if the youth reported earning tips.

Tenure in food service industry: As a proxy for cumulative exposure to norms, tenure in food service industry measures the cumulative number of years an individual had worked in the industry. NLSY97 contains data on all the jobs a respondent held for the past year. Therefore, an individual's tenure in the food service industry was calculated by summing each food service job's tenure from 1997 to 2002 . Moreover, this variable uses year as the measurement unit, and refers to the actual total length of time one had worked in the unit of year. For example: if one respondent had been worked in the food service industry for total 26 weeks by 2002 , then his or her tenure in the food 
service industry is 0.5 year, even if there were employment gaps between the 26 weeks.

Shifts: Since working at evenings is the main focus, five shift categories, i.e., regular evening, irregular, rotate, split and others, were used to capture those who work at evenings. The reference group for shift variable is others, which include regular day shift, night shift, or any other shifts.

Number of jobs: Number of total current jobs is used to measure the number of jobs held by the respondents at the time of the interview.

\section{Control Variables}

Previous substance use: One of the major contributions of this study is the inclusion of previous substance use as a control to minimize unobserved heterogeneity. Much of the previous research on the workplace risk factors were correlational studies that gave little recognition to individuals' substance use behavior prior to the influence of workplace factors. The current study takes advantage of the longitudinal data, which contains extensive information on individuals' histories of substance use, to more cleanly control for self-selection. In other words, if any job-related risk factors are significantly correlated with current substance use, one can conclude the use is a function of current job features without being confounded by prior use. Previous substance use was comprised of previous alcohol use, previous marijuana use, and previous cocaine or other illicit drug use, collected in round five (2001) in the same manner as the dependent variables.

Tenure in non-food service industry: To account for the unobserved effect of experience in another industry on youth substance use, one's tenure in non-food service 
industries was controlled. Measurement for this variable was similar to that of tenure in the food service industry.

Marriage: Marriage has been consistently shown to be a significant protective factor to youth substance use. A marriage dummy variable was set to be one if a respondent was married at the time of the interview. In other cases when a respondent was separated, divorced, widowed or never married, the marriage dummy was coded as zero.

Highest Grade Completed: Academic achievement is another indicator of youth risky or deviant behaviors. This study measures academic performance by respondents' highest grade completed at the time of the interview.

Income: Respondents' socio-economical status is controlled by an income variable, which is measured by total gross household income in the past year. If the respondent was independent, this variable reflects the individual's income over the year. If the respondent was married or lived with parents, the variable indicates the household income.

Peer substance use: Affiliation with substance use peers was measured by two variables with five-point Lickert type scales indicating the proportion of youth in the respondent's grade who got drunk at least once a month or used illicit drugs ( 1 - almost or under $10 \% ; 2$ - under $25 \% ; 3$ - nearly half; 4 - more than $75 \%$; and 5 - almost all or over 90\%). These questions were only asked in the first round (1997). 


\section{Analytical Plan}

The current analytical plan employs two techniques. Multinomial logistic regression with three categories of outcomes is used to test self-selection into the food service industry. Ordinary least squares (OLS) regression with logarithmic transformation of the dependent variable is used to analyze job-related risk factors for food service employee substance use. Self selection of substance users into the food service industry was tested by examining the logistic coefficients for the substance use variables in the food service equation component of the multinomial logistic regression. For the food service employees, t-tests of the regression coefficients for the job-related risk factors were used to test the hypotheses. The set of occupation dummy variables were tested for equality, rather than simply tested for difference from zero. The rest of this section will discuss the analytical strategies in more detail.

Multinomial logistic regression is a well-suited analytic technique when the goal is to assess the relationship between a vector of independent variables, and a non-ordinal, mutually exclusive categorical dependent variable. When there are $K$ categorical outcomes, multinomial logistic regression simultaneously performs a series of $K-1$ binary logistic regression equations, each of which compares each categorical outcome to the baseline group. Separate exponential beta coefficients are produced by multinomial logistics regression for all independent variables for each category of the dependent variables, except for the comparison group. The coefficients represent the percentage change in the odds of being in the dependent variable category versus the comparison group, when there is one unit change in the independent variable. 
In the current study, multinomial logistic regression is used to estimate the association between previous substance use and employment in the food service industry. However, according to a number of SAMHSA reports over the years, three other industries were consistently connected with a high proportion of heavy drinking or drugusing employees. These three high use industries were construction, mining, and arts/entertainment industries. In order to test the self-selection effect into the food service industry, self-selection into other high use industries needed to be controlled for. Therefore, multinomial logistic regression was applied and the dependent variable was divideded into three potential employment outcomes, food service, other high use industries and low use industries. Low use industries served as the comparison group. The CATMOD procedure of SAS 9.1 was used to fit the multinomial logistic regression model. Two logistic regression equations were estimated. In particular, the first group of coefficients estimated the percentage change in the odds of working in other high use industries versus working in low use industries. The second group of coefficients, which estimated the percentage change in the odds of working in the food service industry versus working in low use industries, is the focus of this thesis. According to the selfselection hypothesis, the second group of logistic coefficients for the substance use variables should be greater than zero if a self-selection effect exists. OLS regression was employed for hypotheses two through six where the dependent variables are interval measures of substance use. OLS regression models the relationship between explanatory variables and a response variable by fitting a linear equation; the dependent variable is a function of a linear combination of the explanatory variables. The regression coefficients 
for the explanatory variables represent the change in the dependent variable associated with a one unit change in the explanatory variable.

A logarithmic transformation on current and previous substance use was used to correct for heteroscedasticity. In particular, since the substance use measurements ranged from zero to some large positive number (30 days consumed alcohol in the past month, 500 times used cocaine in the previous year) and most respondents were not engaged in substance use, fitting a regression model directly on the data violated the constant variance assumption of OLS. Log transformation of the dependent variable is a commonly used technique to correct for right-skewed data. The zero values in the substance use variables pose a problem for log transformations. The usual remedy for this is to transform the zeros to a value close to zero. The current study adopted this method and selected the appropriate transformed value for zero by model fit convergence. Specifically, 0 was transformed to be the antilog of -0.2 for days using alcohol; -0.9 for days of binge use of alcohol; -0.5 for number of drinks per day; -1.3 for days using marijuana; and lastly -1.5 for times using cocaine or other illicit drugs.

After log transformation on both previous and current substance use, the regression models were fitted by the SAS REG procedure. When holding other variables constant, a one percent change in previous substance use would change current substance use by $100 *$ coefficient percent. For other non-transformed explanatory variables, the regression coefficients are estimates of the percentage change in substance use when there is a one unit change in an explanatory variable. The percentage change is equal to $100 *$ coefficient. 
A one-tailed test of the regression coefficients for the job-related risk factors was used to test all but one of the hypotheses. For the hypothesis that compared employee substance use between occupations the difference between regression coefficients was tested for difference from zero using a one-tailed test (Paternoster, Brame, Mazerolle, \& Piquero, 2006). Specifically, the equation for a test between two coefficients is:

$$
Z=\frac{b_{1}-b_{2}}{\sqrt{S E b_{1}^{2}+S E b_{2}^{2}}}
$$


Variable

Dependent Variables

Days alcohol use

Days binge alcohol use

Average Number of alcoholic beverage per day

Days marijuana use

Times cocaine or other

illicit drugs use

Independent Variables

Occupation

Bartender

Server

Back-of-the-house

Others

Shift

Evening

Rotate

Split

Irregular

Others

Tips

Food service tenure

Number of jobs
Definition

Number of days used one or more alcoholic beverage(s) in the past 30 days

Number of days used five or more alcoholic beverages in the past 30 days

Number of alcoholic beverage(s) consumed on the days when the respondent drinks

Number of days smoked marijuana in the past 30 days

Number of times used cocaine or other illicit drugs (such as crack, heroin, etc.) in past year

Equals 1 if occupation is 4040 according to 2002 Census code Equals 1 if occupation is 4110 or 4120

Equals 1 if worked as chef or head cook, cook, or food preparation worker, occupation 4000, 4020, 4030, 4220, 4140, 4650

Equals 1 if worked as server and food preparation worker, cashier, host, manager, clerk, janitor, security or other, occupation 20, 130, $310,620,2340,3910,4010,4050,4060,4130,4150,4160,4720$, 4760, 4950 and above

Equals 1 if worked regular evening shifts

Equals 1 if worked rotating shifts

Equals 1 if worked split shifts

Equals 1 if worked irregular shifts

Equals 1 if worked regular day shifts, regular night shifts, and others. Equals 1 if reported earning tips

Number of cumulative years worked in the food service industry

Total number of jobs held currently

Table 2.1: Definitions of Model Variables (Cont.) 
Table 2.1 Cont.

Variable Definition

Covariates

Age

Male

Race

African American

Hispanic / Latino

Asian \& Pacific Islander

Native American

Others

Married

Highest grade completed

Income

Non-food job tenure

Previous substance use

Days alcohol use

Respondents' ages by the date of interview

Equals 1 if male, 0 if female

Equals 1 if is African American, 0 if not

Equals 1 if Hispanic or Latino, 0 if not

Equals 1 if Asian or Pacific Islander, 0 if not

Equals 1 if Native American, 0 if not

Equals 1 if non-White and none of the above race, 0 if not

Equals 1 if was currently married, 0 if had never married, separated, divorced or widowed

The highest grade level completed by the date of interview Total gross household income measured in $\$ 1000$

Number of cumulative years worked in non-food service

industry

Number of days consumed one or more alcoholic beverage(s) in the previous 30 days

Days binge alcohol use

Number of days consumed five or more alcoholic beverages in the previous 30 days

Average Number of alcoholic beverage per day

Days marijuana use

Times cocaine or other illicit drugs use

Number of alcoholic beverage(s) consumed on the days when the respondent drinks

Number of days smoked marijuana in the previous 30 days

Number of times used cocaine or other illicit drugs

(such as crack, heroin, etc.) in past year

Proportion of students in the same grade got drunk at least once a month in 1997

Peer illicit drug use

Proportion of students in the same grade used illegal drugs in 1997 


\begin{tabular}{|c|c|c|}
\hline Variable (2001) & Mean (Std) & Proportions \\
\hline Age & $19.08(1.41)$ & \\
\hline Male & & .50 \\
\hline White & & .58 \\
\hline Asian/Pacific Islander & & .02 \\
\hline African American & & .22 \\
\hline Hispanic/ Latino & & .12 \\
\hline Native American & & .01 \\
\hline Other & & .05 \\
\hline Married & & .07 \\
\hline Highest grade completed & $11.89(1.86)$ & \\
\hline Peer alcohol use & $2.15(1.22)$ & \\
\hline Peer drug use & $2.30(1.28)$ & \\
\hline Income $(\$ 1000)$ & $35.73(49.53)$ & \\
\hline Days use alcohol & $3.52(5.77)$ & \\
\hline Days binge alcohol use & $1.62(3.85)$ & \\
\hline No. alcohol per day & $2.92(5.94)$ & \\
\hline Days use marijuana & $2.36(6.97)$ & \\
\hline Times other illicit drug use & $2.10(20.03)$ & \\
\hline Total jobs & $1.66(1.05)$ & \\
\hline Tenure in food service ind. & $0.37(0.78)$ & \\
\hline Tenure in CMA ind. & $0.11(0.44)$ & \\
\hline Tenure in other ind. & $1.19(1.44)$ & \\
\hline Work in food service ind. & & .19 \\
\hline Work in construction etc. & & .07 \\
\hline 2002 in food service ind. & & .16 \\
\hline 2002 in construction etc. ind. & & .06 \\
\hline
\end{tabular}

Table 2.2: Descriptive Statistics of the Self-Selection Sample $(n=4704)$ 


\begin{tabular}{|c|c|c|c|c|c|}
\hline Variable (2002) & $\begin{array}{l}\text { Days use } \\
\text { alcohol } \\
(\mathrm{n}=764)\end{array}$ & $\begin{array}{l}\text { Days binge } \\
\text { use of alcohol } \\
(\mathrm{n}=763)\end{array}$ & $\begin{array}{l}\text { No. of drinks } \\
(\mathrm{n}=764)\end{array}$ & $\begin{array}{l}\text { Days use } \\
\text { marijuana } \\
(\mathrm{n}=766)\end{array}$ & $\begin{array}{l}\text { Times use } \\
\text { other drug } \\
(\mathrm{n}=765)\end{array}$ \\
\hline Previous use & $1.95(3.06)$ & $0.92(3.04)$ & $1.71(2.98)$ & $0.68(4.48)$ & $0.12(0.34)$ \\
\hline Dependent var. & $2.27(3.12)$ & $0.94(3.00)$ & $1.85(2.84)$ & $0.69(4.64)$ & $0.12(3.89)$ \\
\hline Tenure in food ind. & $1.84(1.35)$ & $1.84(1.35)$ & $1.84(1.35)$ & $1.83(1.35)$ & $1.84(1.35)$ \\
\hline $\begin{array}{l}\text { Tenure in non-food } \\
\text { service ind. }\end{array}$ & $57.08(1.26)$ & $1.10(1.27)$ & $1.10(1.26)$ & $1.10(1.26)$ & $1.10(1.26)$ \\
\hline No. of jobs & $1.16(0.42)$ & $1.16(0.42)$ & $1.16(0.42)$ & $1.57(0.42)$ & $1.16(0.42)$ \\
\hline No. of food jobs & $1.02(0.16)$ & $1.02(0.16)$ & $1.02(0.16)$ & $1.02(0.16)$ & $1.02(0.16)$ \\
\hline Age & $19.77(1.39)$ & $19.77(1.39)$ & $19.77(1.39)$ & $19.78(1.40)$ & $19.78(1.40)$ \\
\hline Male & 0.45 & 0.45 & 0.45 & 0.45 & 0.45 \\
\hline Asian/Pacific & 0.02 & 0.02 & 0.02 & 0.02 & 0.02 \\
\hline African American & 0.22 & 0.22 & 0.22 & 0.22 & 0.22 \\
\hline Hispanic & 0.10 & 0.10 & 0.10 & 0.10 & 0.10 \\
\hline Native American & 0.01 & 0.01 & 0.01 & 0.01 & 0.01 \\
\hline Other race & 0.04 & 0.04 & 0.04 & 0.04 & 0.04 \\
\hline Highest grade & $12.17(1.52)$ & $12.17(1.51)$ & $12.17(1.52)$ & $12.18(1.52)$ & $12.18(1.52)$ \\
\hline Married & 0.06 & 0.06 & 0.06 & 0.06 & 0.06 \\
\hline Peer alcohol use & $2.05(1.44)$ & $2.05(1.20)$ & $2.05(1.20)$ & $2.05(1.20)$ & $2.05(1.20)$ \\
\hline Peer drug use & $2.30(1.74)$ & $2.30(1.32)$ & $2.30(1.32)$ & $2.30(1.32)$ & $2.30(1.32)$ \\
\hline Income & $36.20(47.26)$ & $36.25(47.28)$ & $36.20(47.26)$ & $36.11(47.23)$ & $36.08(47.26)$ \\
\hline Bartender & 0.02 & 0.02 & 0.02 & 0.02 & 0.02 \\
\hline Server & 0.25 & 0.25 & 0.25 & 0.25 & 0.25 \\
\hline Back-of-the-house & 0.28 & 0.28 & 0.28 & 0.28 & 0.28 \\
\hline Evening & 0.20 & 0.20 & 0.20 & 0.20 & 0.20 \\
\hline Rotating & 0.17 & 0.17 & 0.17 & 0.17 & 0.17 \\
\hline Split & 0.02 & 0.02 & 0.02 & 0.02 & 0.02 \\
\hline Irregular & 0.10 & 0.10 & 0.10 & 0.10 & 0.10 \\
\hline Tips & 0.39 & 0.39 & 0.39 & 0.39 & 0.39 \\
\hline
\end{tabular}

Note: Data are reported as means(std) or proportions.

Table 2.3: Descriptive Statistics of the Food Service Worker Sample 


\section{CHAPTER 3}

\section{RESULTS}

\section{Self-Selection Hypothesis}

Hypothesis 1 proposed a self-selection effect for substance use on employment in the food service industry. It viewed the food service employee's substance use problem as a consequence of substance users' self-selection into their employment. Previous substance use was hypothesized to increase one's likelihood to work for the food service industry. Multinomial logistic regression was used to estimate the effects of substance use on the odds of employment in the food service industry, which were then used to test the hypothesis. The estimated multinomial logit coefficient for the food service industry, other high use industries, and other low use industries were tested to see if they were greater than zero.

There was partial support for the self-selection hypothesis. Binge use of alcohol and marijuana use had significant positive effects on the odds of employment in food service. The multinomial logit coefficients indicated that for every additional day an individual engaged in binge alcohol use, his or her odds of working for food service, compared to working for a low-use industry, increased by 5.37 percent. For every 
additional day an individual engaged in marijuana use, the odds increased by 1.41 percent. Number of days drinking, however, had a negative effect on the odds of becoming employed in food service. Specifically, for every additional day an individual engaged in alcohol use, the odds decreased by 2.33 percent. The other two substance use measures, number of drinks consumed per occasion and other illicit drugs use, were not significant predictors of the odds of employment in food service. Individual characteristics also predicted employment in food service. Table 3.1 summarizes the logit coefficients for all the explanatory variables.

The multinomial logit model also estimated the odds of employment in other high use industries compared to low use industries. Although previous substance use was expected to predict self-selection into other higher use industries, none of the substance use variables were significant. Like food service, individual characteristic significantly predicted the odds of employment in these high use industries. Detailed results for the other high use industries are attached in Appendix B. 


\begin{tabular}{|c|c|c|}
\hline $\mathrm{n}=4704$ & $\begin{array}{l}\text { Logit } \\
\text { Coefficients }\end{array}$ & $\begin{array}{l}\text { Standard } \\
\text { Error }\end{array}$ \\
\hline Intercept & 0.63 & 0.86 \\
\hline Age & -0.06 & 0.05 \\
\hline Male & $-0.21 * *$ & 0.10 \\
\hline Asian / Pacific Islander & -0.28 & 0.34 \\
\hline African American & $-0.15^{*}$ & 0.12 \\
\hline Latino / Hispanic & -0.07 & 0.18 \\
\hline Native American & -0.01 & 0.43 \\
\hline Other race & $-0.36^{*}$ & 0.27 \\
\hline Married & 0.08 & 0.18 \\
\hline Highest grade completed & $-0.14 * * *$ & 0.04 \\
\hline Peer alcohol use & $-0.08^{*}$ & 0.06 \\
\hline Peer drug use & $0.11 * *$ & 0.05 \\
\hline Income $(\$ 1000)$ & 0.00 & 0.00 \\
\hline Previously work in this ind. & $2.35 * * *$ & 0.10 \\
\hline Previous tenure in this ind. & $0.37 * * *$ & 0.06 \\
\hline Previous tenure in lower use ind. & $-0.14 * * *$ & 0.05 \\
\hline Total jobs in previous year & $-0.10 * *$ & 0.05 \\
\hline Days use alcohol & $-0.02 *$ & 0.01 \\
\hline Days binge use alcohol & $0.05^{* * *}$ & 0.02 \\
\hline No. drinks per day & 0.01 & 0.01 \\
\hline Days use marijuana & $0.01 * *$ & 0.01 \\
\hline Times use other illicit drug & 0.00 & 0.00 \\
\hline \multicolumn{3}{|c|}{$\begin{array}{l}\text { Note: } p \text {-values reflect one-tailed test. } \\
\text { Likelihood ratio }{ }^{3} \text { : Chi-squre }=4185.33, p=1\end{array}$} \\
\hline $\begin{array}{l}p<.1 * \\
p<.05 * * \\
p<.01 * * *\end{array}$ & & \\
\hline
\end{tabular}

Table 3.1: Multinomial logistic regression coefficients for employment in the food service industry

\footnotetext{
${ }^{3}$ As some of the explanatory variables are continuous, likelihood ratio is not an appropriate model fit statistic (Clark, 2004).
} 


\section{Substance Use Hypotheses}

A series of five semi-logarithmic regressions were used to test whether the proposed job-related risk factors predicted food service employees' substance use, which are assessed by five measurements. An alpha level of .05 was used for all statistical tests. All the p-values reported in the results were based on one-tailed tests. F-statistics for all five models were significant ( $\mathrm{p}$-value $<.01$ ). Reduced models with only covariates included were compared to the full models using F-tests and yielded strong evidence to support the full models (Appendix C). All the effects reported in this section were ceteris paribus. Table 3.2 lists all the regression results for the job-related risk factors for substance use.

Hypothesis 2 was derived from the availability perspective, which predicted a higher level of alcohol consumption among bartenders, compared with other occupation groups in the food service industry. The regression coefficient for bartenders is the estimated difference between bartenders and the reference group including hosts, cashiers, managers, administrators, etc. A t-test for equality of regression coefficients in the same model was employed to compare the regression coefficient for bartenders with that for servers and back-of-the-house workers. Hypothesis 2 was partially supported. Bartenders reported more days of alcohol use than all the other food service occupations. In terms of binge alcohol use, bartenders reported more days than back-of-the-house and the reference group. But bartenders did not differ with other occupation groups in number of drinks consumed per occasion. Bartenders reported 73.22 percent more days of alcohol use than the reference group, 64.76 percent more days than server $(t=2.38, p$ 
$<.01)$, and 75.16 percent more days than back-of-the-house $(\mathrm{t}=2.81, \mathrm{p}<.01)$.

Bartenders also engaged in 48.78 percent more days in binge drinking than the reference group, 43.04 percent more days than servers $(\mathrm{t}=1.61, \mathrm{p}=.06)$, and 47.37 percent more days than back-of-the-house $(\mathrm{t}=1.80, \mathrm{p}=.04)$. In terms of number of drinks, bartenders did not differ from the reference group. Nor was there any significant difference between bartenders and servers $(\mathrm{t}=0.19, \mathrm{p}=.85)$ or back-of-the-house $(\mathrm{t}=0.04, \mathrm{p}=.88)$.

Hypothesis 3 stated that extra cash resources from tip earnings would contribute to more alcohol or illicit drug use. After controlling for total income, the regression coefficient for the tip dummy variable was compared to zero in all substance use equations to test whether earning tips contributed to more use. Results supported the hypothesis for number of drinks at $\alpha=.05$ level, and days of alcohol use, days of binge alcohol use and marijuana use measurement at $\alpha=.1$ level. However, there was no support for the hypothesis for other illicit drug use. More specifically, earning tips had a significant positive effect on the number of alcoholic beverages consumed on each occasion. Food service employees who earned tips consumed 15.28 percent more drinks on each occasion. Earning tips also increased days of alcohol use, days of binge alcohol use and days of marijuana use at $\alpha=.1$ level. Tip earning employees drank 13.64 percent more days, binge drank 12.70 percent more days and used marijuana 15.96 percent more days.

Based on norms theory, hypothesis 4 predicted increasing levels of substance use as individuals accumulated more exposure to the substance use norms within the food service industry. The hypothesis was tested by comparing the regression coefficients 
for the tenure in food service jobs to zero in all of the substance use equations.

Hypothesis 4 was not supported in any of the substance use equations. After controlling for previous use and other individual or job-related variables, cumulative exposure in the food service industry had no significant effect on one's alcohol or illicit drug use.

Hypothesis 5 stated that individuals who worked the regular evening shift would have higher levels of substance use. Using employees who worked day and other shifts as the reference group, the regression coefficients of the shift variables were compared to zero to test the hypothesis. On the whole, there was no support for hypothesis 5. None of the shift variables had an effect that was significant at the .05 level. Three of the four shift variables had a significant effect $(\alpha=.1)$ in at least one equation, for a total of five significant effects. However, four of the five significant variables did not have the predicted sign. Evening shift employees reported 17.87 percent more other illicit drug use than the reference group of employees. Contrary to the hypothesis, evening shift employees used alcohol 14.89 percent fewer days and binge use alcohol 14.28 percent fewer days than the reference group. Split shift employees used illicit drugs 58.04 percent fewer times than the reference group. Moreover, employees who worked irregular shifts used alcohol 16.36 percent fewer days than the reference group.

Derived from stress theory, hypothesis 6 predicted increasing substance use as an individual held more jobs. Regression coefficients of the total number of jobs variable was compared to zero to test this hypothesis. Hypothesis 6 was supported for alcohol use, but not supported for marijuana and other illicit drug use. Holding more jobs was found to increase days of alcohol use, days of binge alcohol use, and number of drinks 
consumed per occasion. Specifically, having any one additional job would increase one's days of alcohol use by 18.76 percent, increase one's days of binge alcohol use by 18.76 percent, and increase one's number of drinks consumed by 15.45 percent. However, having one additional job was not related to one's marijuana or other illicit drug use.

\section{Model Significance}

An F-test was used to estimate overall significance of the hypothesized jobrelated risk factors within the five substance use models. Results showed that proposed risk factors as a whole were significant predictors for the days of alcohol use $(\mathrm{p}<.01)$, days of binge alcohol use $(\mathrm{p}=.04)$, other illicit drug use $(\mathrm{p}=.05)$, and non-significant for number of drinks ( $\mathrm{p}=.54)$ or marijuana use $(\mathrm{p}=.79)$. 


\begin{tabular}{|c|c|c|c|c|c|}
\hline & $\begin{array}{l}\text { Days use } \\
\text { alcohol } \\
(\mathrm{n}=764)\end{array}$ & $\begin{array}{l}\text { Days binge use } \\
\text { alcohol } \\
(\mathrm{n}=763)\end{array}$ & $\begin{array}{l}\text { No. drinks per } \\
\text { day } \\
(\mathrm{n}=764)\end{array}$ & $\begin{array}{l}\text { Marijuana use } \\
(\mathrm{n}=766)\end{array}$ & $\begin{array}{l}\text { Other illicit } \\
\text { drug use } \\
(\mathrm{n}=765)\end{array}$ \\
\hline Intercept & $\begin{array}{l}-0.68 \\
(0.61)\end{array}$ & $\begin{array}{l}-0.10 \\
(0.60)\end{array}$ & $\begin{array}{l}-0.15 \\
(0.59)\end{array}$ & $\begin{array}{l}1.13^{*} \\
(0.80)\end{array}$ & $\begin{array}{l}-0.78 \\
(0.78)\end{array}$ \\
\hline Previous use & $\begin{array}{l}0.50^{* * *} \\
(0.03)\end{array}$ & $\begin{array}{l}0.49^{* * *} \\
(0.03)\end{array}$ & $\begin{array}{l}0.43^{* * *} \\
(0.03)\end{array}$ & $\begin{array}{l}0.59^{* * *} \\
(0.03)\end{array}$ & $\begin{array}{l}0.45^{* * *} \\
(0.03)\end{array}$ \\
\hline Age & $\begin{array}{l}0.03 \\
(0.03)\end{array}$ & $\begin{array}{l}-0.03 \\
(0.03)\end{array}$ & $\begin{array}{l}0.01 \\
(0.03)\end{array}$ & $\begin{array}{l}-0.06 \\
(0.05)\end{array}$ & $\begin{array}{l}-0.04 \\
(0.04)\end{array}$ \\
\hline Male & $\begin{array}{l}0.14 * * \\
(0.08)\end{array}$ & $\begin{array}{l}0.25^{* * *} \\
(0.07)\end{array}$ & $\begin{array}{l}0.18^{* * *} \\
(0.07)\end{array}$ & $\begin{array}{l}0.30^{* * *} \\
(0.10)\end{array}$ & $\begin{array}{l}-0.01 \\
(0.10)\end{array}$ \\
\hline $\begin{array}{l}\text { Asian/Pacific } \\
\text { Islanders }\end{array}$ & $\begin{array}{l}0.09 \\
(0.26)\end{array}$ & $\begin{array}{l}-0.16 \\
(0.25)\end{array}$ & $\begin{array}{l}-0.19 \\
(0.25)\end{array}$ & $\begin{array}{l}0.01 \\
(0.34)\end{array}$ & $\begin{array}{l}0.17 \\
(0.33)\end{array}$ \\
\hline African American & $\begin{array}{l}-0.15^{* *} \\
(0.09)\end{array}$ & $\begin{array}{l}-0.25^{* * *} \\
(0.09)\end{array}$ & $\begin{array}{l}-0.17^{* *} \\
(0.09)\end{array}$ & $\begin{array}{l}-0.11 \\
(0.12)\end{array}$ & $\begin{array}{l}-0.12 \\
(0.12)\end{array}$ \\
\hline Latino/Hispanic & $\begin{array}{l}-0.07 \\
(0.14)\end{array}$ & $\begin{array}{l}0.03 \\
(0.13)\end{array}$ & $\begin{array}{l}-0.08 \\
(0.13)\end{array}$ & $\begin{array}{l}-0.30^{*} \\
(0.18)\end{array}$ & $\begin{array}{l}-0.02 \\
(0.18)\end{array}$ \\
\hline Native American & $\begin{array}{l}0.07 \\
(0.31)\end{array}$ & $\begin{array}{l}0.16 \\
(0.30)\end{array}$ & $\begin{array}{l}-0.13 \\
(0.30)\end{array}$ & $\begin{array}{l}-0.81^{* *} \\
(0.42)\end{array}$ & $\begin{array}{l}-0.05 \\
(0.41)\end{array}$ \\
\hline Other race & $\begin{array}{l}0.07 \\
(0.21)\end{array}$ & $\begin{array}{l}0.06 \\
(0.20)\end{array}$ & $\begin{array}{l}0.07 \\
(0.20)\end{array}$ & $\begin{array}{l}0.00 \\
(0.28)\end{array}$ & $\begin{array}{l}-0.19 \\
(0.27)\end{array}$ \\
\hline $\begin{array}{l}\text { Highest grade } \\
\text { completed }\end{array}$ & $\begin{array}{l}0.02 \\
(0.03)\end{array}$ & $\begin{array}{l}0.01 \\
(0.03)\end{array}$ & $\begin{array}{l}-0.01 \\
(0.03)\end{array}$ & $\begin{array}{l}-0.03 \\
(0.04)\end{array}$ & $\begin{array}{l}-0.01 \\
(0.03)\end{array}$ \\
\hline Married & $\begin{array}{l}-0.22 * \\
(0.15)\end{array}$ & $\begin{array}{l}-0.30^{* *} \\
(0.14)\end{array}$ & $\begin{array}{l}-0.23^{*} \\
(0.14)\end{array}$ & $\begin{array}{l}-0.18 \\
(0.20)\end{array}$ & $\begin{array}{l}-0.18 \\
(0.19)\end{array}$ \\
\hline Peer alcohol use & $\begin{array}{l}0.06^{*} \\
(0.04)\end{array}$ & $\begin{array}{l}0.05 \\
(0.04)\end{array}$ & $\begin{array}{l}0.06^{*} \\
(0.04)\end{array}$ & $\begin{array}{l}0.00 \\
(0.06)\end{array}$ & $\begin{array}{l}0.00 \\
(0.06)\end{array}$ \\
\hline Peer drug use & $\begin{array}{l}-0.00 \\
(0.04)\end{array}$ & $\begin{array}{l}0.02 \\
(0.04)\end{array}$ & $\begin{array}{l}-0.03 \\
(0.04)\end{array}$ & $\begin{array}{l}0.05 \\
(0.05)\end{array}$ & $\begin{array}{l}0.03 \\
(0.05)\end{array}$ \\
\hline Income & $\begin{array}{l}0.55 \\
(0.75)\end{array}$ & $\begin{array}{l}-0.94 \\
(0.74)\end{array}$ & $\begin{array}{l}0.22 \\
(0.73)\end{array}$ & $\begin{array}{l}-0.42 \\
(1.01)\end{array}$ & $\begin{array}{l}1.64 * * \\
(0.98)\end{array}$ \\
\hline Work intensity & $\begin{array}{l}-0.00 \\
(0.00)\end{array}$ & $\begin{array}{l}0.00 \\
(0.00)\end{array}$ & $\begin{array}{l}-0.00 \\
(0.00)\end{array}$ & $\begin{array}{l}0.00 \\
(0.00)\end{array}$ & $\begin{array}{l}0.01 \\
(0.00)\end{array}$ \\
\hline $\begin{array}{l}\text { Tenure in non-food } \\
\text { service ind. }\end{array}$ & $\begin{array}{l}0.02 \\
(0.03)\end{array}$ & $\begin{array}{l}0.00 \\
(0.03)\end{array}$ & $\begin{array}{l}0.01 \\
(0.03)\end{array}$ & $\begin{array}{l}0.02 \\
(0.04)\end{array}$ & $\begin{array}{l}-0.01 \\
(0.04)\end{array}$ \\
\hline \multicolumn{6}{|c|}{$\begin{array}{l}\text { Note: Significance levels reflect one-tailed tests. } \\
\mathrm{p}<.1^{*} \\
\mathrm{p}<.05^{* *} \\
\mathrm{p}<.01^{* * *}\end{array}$} \\
\hline
\end{tabular}

Table 3.2: OLS results of job-related risk factors for substance use in the food service industry (Cont.) 
Table 3.2 Cont.

\begin{tabular}{llllll} 
& $\begin{array}{l}\text { Days use } \\
\text { alcohol } \\
(\mathrm{n}=764)\end{array}$ & $\begin{array}{l}\text { Days binge } \\
\text { use alcohol } \\
(\mathrm{n}=763)\end{array}$ & $\begin{array}{l}\text { No. drinks per } \\
\text { day } \\
(\mathrm{n}=764)\end{array}$ & $\begin{array}{l}\text { Marijuana use } \\
(\mathrm{n}=766)\end{array}$ & $\begin{array}{l}\text { Other illicit } \\
\text { drug use } \\
(\mathrm{n}=765)\end{array}$ \\
\hline $\begin{array}{l}\text { Tenure in food } \\
\text { service ind. }\end{array}$ & 0.00 & 0.03 & 0.01 & -0.01 & -0.03 \\
No. of jobs & $(0.03)$ & $(0.03)$ & $(0.03)$ & $(0.04)$ & $(0.04)$ \\
& $0.19^{* *}$ & $0.19^{* *}$ & $0.15^{* *}$ & 0.09 & 0.10 \\
Bartender & $(0.09)$ & $(0.09)$ & $(0.04)$ & $(0.12)$ & $(0.11)$ \\
& $0.73^{* * *}$ & $0.50^{* *}$ & 0.05 & 0.02 & $1.02^{* * *}$ \\
Server & $(0.25)$ & $(0.25)$ & $(0.25)$ & $(0.34)$ & $(0.33)$ \\
& 0.08 & 0.06 & 0.04 & $-0.20^{*}$ & 0.06 \\
Back-of-the-house & $(0.10)$ & $(0.10)$ & $(0.10)$ & $(0.13)$ & $(0.13)$ \\
& -0.02 & 0.01 & 0.09 & -0.06 & 0.06 \\
Evening shift & $(0.09)$ & $(0.09)$ & $(0.08)$ & $(0.12)$ & $(0.11)$ \\
Rotating shift & $-0.15^{*}$ & $-0.14^{*}$ & -0.05 & -0.12 & $0.18^{*}$ \\
& $(0.10)$ & $(0.09)$ & $(0.09)$ & $(0.12)$ & $(0.12)$ \\
Split shift & -0.06 & 0.00 & -0.00 & -0.15 & -0.00 \\
Irregular shift & $(0.10)$ & $(0.09)$ & $(0.09)$ & $(0.13)$ & $(0.12)$ \\
& 0.25 & 0.18 & 0.12 & -0.08 & $-0.58^{* *}$ \\
Tips & $(0.26)$ & $(0.25)$ & $(0.25)$ & $(0.35)$ & $(0.34)$ \\
& $-0.16^{*}$ & -0.10 & -0.00 & -0.18 & 0.13 \\
\hline $\mathrm{R}^{2}$ & $(0.12)$ & $(0.12)$ & $(0.12)$ & $(0.16)$ & $(0.16)$ \\
F-statistic & $0.14^{*}$ & $0.13^{*}$ & $0.15^{* *}$ & $0.16^{*}$ & -0.01 \\
& $(0.09)$ & $(0.08)$ & $(0.08)$ & $(0.12)$ & $(0.11)$ \\
\hline & 37.73 & 36.20 & 29.63 & 38.16 & 26.32 \\
& 17.89 & 16.73 & 12.43 & 18.26 & 10.56 \\
& & & & &
\end{tabular}

Note: Significance levels reflect one-tailed tests.

$\mathrm{p}<.1 *$
$\mathrm{p}<.05 * *$
$\mathrm{p}<.01 * * *$ 


\section{CHAPTER 4}

\section{DISCUSSION}

Past epidemiology studies and government surveys have consistently shown a noteworthy substance use problem in the food service industry. However, both empirical and theoretical investigations of workplace risk factors in the food service industry have been limited. A number of related studies called for future research to fully examine the reasons for a strong substance use norm in this industry (e.g., Corsun \& Young, 1998; Stubbs, 2001). To increase our knowledge of the problem, the present research started the comprehensive investigation by examining a self-selection effect, which was an alternative explanation for the prevalent alcohol and illicit drug use in the food service industry. The study then analyzed several job-related risk factors along with extensive individual backgrounds, using the NLSY97 cohort. Besides testing availability theory, norm theory and stress theory, specific features of food service jobs such as bartending, working evening shift, and tip earning were examined. A key advantage of using the NLSY97 cohort is the extensive information on individual backgrounds and substance use histories that were unmeasured by past workplace research.

By conducting a wide-scale investigation among young food service employees, 
the current study contributes to literature in five aspects. First, this study, by employing a representative panel data, is a methodological improvement over similar past research. Second, unlike most studies in general workplace substance use, the current research has focused on the food service industry and is expected to improve the understanding of the specific industry features linked with substance use (Ramchand, 2003). Third, by exploring a comprehensive set of predictors, this study is able to control for unobserved heterogeneity (e.g., previous substance use) and thus show the actual contributing effect of the job on employee substance use. Fourth, this study fills in research gap by studying illicit drug use in the food service industry. Finally, this research is one of the first to investigate employee self-selection, which is an alternative approach to unravel the high prevalence in the food service industry (Larsen, 1994).

The findings of the current study can be summed briefly in four folds manner. First and foremost, after accounting for previous substance use and a number of individual risk factors, bartending, holding multiple jobs, and tip earning were three key risk factors for substance use among food service employees. In addition, among the five substance use models, employee alcohol use was best predicted by the proposed job risk factors. Next, there is some evidence for employee self-selection among binge-drinkers and marijuana users. Fourth, cumulative exposure to the permissive norms and working evening shift were not significant predictors of employee substance use in the food service industry. Throughout the reminder of the chapter, interpretations and implications of the results are discussed in detail. Practical implementation and considerations for both food service practitioners and employees are presented. Last but 
not least, limitations of the study are discussed, followed by opportunities for future research.

\section{Discussion}

One major contribution of the current research is that it identified three job-related risk factors for substance use among food service employees. The three risk factors were: bartending, holding multiple jobs, and tip earning. After controlling for a comprehensive set of individual characteristics, including previous use, these three jobrelated factors remained strong predictors to employee alcohol use. Each of these three risk factors influenced alcohol use based on different theoretical premises and in different manners, as will be discussed in the following paragraphs.

Bartenders' large involvement in alcohol use was derived from availability theory, which attributes employee drinking to the availability of alcohol at workplace. This perspective was supported for days of alcohol use and days of binge alcohol use.

Bartenders, even with a small sample size, were shown to engage in drinking significantly more often than all the other food service occupations. Bartenders reported drinking 65 percent more days than servers, 75 percent more than back-of-the-house, and 73 percent more than the other food service occupations. Bartenders also reported a greater involvement with binge drinking than back-of-the-house (47 percent more days) and the reference group (50 percent more), but 43 percent more than servers at marginal significance level. The findings on bartenders' alcohol use were consistent with an earlier qualitative study (Stubbs, 2001). More interestingly, the current study also revealed 
bartenders reported more use of other illicit drug than other food service occupations. The differences varied from 102 percent more for the comparison group, to 96 percent more for servers and back-of-the-house. This finding is also consistent with Stubbs (2001).

Although availability theory was the basis for the hypothesis, it remains unknown whether alcohol availability at work was the major contributor to bartenders' alcohol use. Norms or social control can also be related, as some empirical study has suggested bartenders' drinking at work was considered normative by managers and customers, depending on the type of bars (Stubbs, 2001). The current study was unable to measure social control, or to distinguish the type of establishment, due to data restriction. It is therefore imperative for future research to investigate the motivation and patterns of bartenders' alcohol use. Moreover, both Stubbs and the current study reported a greater illicit drug use among bartenders. Little is known to the problem, however. Future research attention is needed to understand bartenders' involvement with non-marijuana illicit drugs.

Holding multiple job was a consistent risk factor for alcohol use among the food service employees. The current research hypothesized that as one held more job, he or she would be involved in more alcohol or illicit drug use. It was argued that multiple jobs induced role overload, increased stress, and then contributed to substance use in order to alleviate stress. After controlling for work intensity, income, as well as previous use, number of jobs remained a strong predictor for alcohol use, suggesting it was the multiple roles that influenced more alcohol use, rather than longer hour, bigger income or 
personal selection. However, multiple job holding was not found related to illicit drug use, suggesting the impact of multiple jobs on alcohol use did not influence illicit drug use.

The finding on multiple job holding is important to the literature. Using number of jobs as a measure for job stress is rare. Previous research had adopted various measures for stress and resulted in mixed conclusions. For example, past studies often attempted to explain adolescent substance use by work intensity. This study demonstrated that number of jobs, rather than work length, contributed to higher alcohol use. Since number of jobs is a simple and direct measure, it may be a promising measure for employee stress. Future research can validate the measure within different context. Since the current result does not entail information as to why multiple jobs lead to heavier alcohol use, future research can further investigate the links between multiple job-holding, employee stress and employee alcohol use.

The finding on multiple job holding is also of great significance to practical implication. Because number of jobs has shown to be a consistent risk factor for employee alcohol use, food service managers can easily identify the risk of alcohol use among employees. Particularly, special attention or accommodation is needed to those who hold multiple jobs. As for the employees with multiple jobs, they need to be aware of the increasing risk of more alcohol use associated with holding multiple jobs, so as to effectively prevent or combat the "bad habit."

The last risk factor identified by this study is tip earning. Food service employees who earned tips reported consuming $15 \%$ more drinks for each additional tip dollar 
earned. Tip earning was also related to days of alcohol use, days of binge alcohol use, and marijuana use, for similar effect sizes but at marginal significance. The findings provided support to the extension of availability theory based on consumer selfdiscipline, suggesting available cash resources contribute to employee alcohol use and marijuana use. Moreover, since income was controlled, results indicated it was the format of earning, not the total amount of earning, that triggered substance use. The finding is consistent with past studies (Shaner et al., 1995; Wallace, 1989).

The current research is the first to establish the link between tip earning and employee substance use. Since a substantial proportion of food service employees earn tips, tips may be a key contributor to the substance use norms in the industry. In order to validate a causal relationship, future study can adopt an experimental study design to investigate the impact of tip earnings on employee substance use. In addition, it would be interesting to examine the interaction between tips and other job conditions, such as number of jobs, shifts, types of food service establishment, etc.

The practical implication of the finding on tip earning is relevant to managers and employees. For managers, it is recommended that they distribute tips with the same options as wages, payroll check or direct deposit. For the employees, awareness of proper money management should be raised, especially among the younger ones. Like other consumers, tip earning workers in the food service industry need to be educated on how to save or how to control spending impulse with their tip incomes.

One final note on the job-related risk factor hypotheses is needed on the overall significance of the job-related risk factors in predicting substance use. Among the five 
substance use models, the proposed job-related risk factors were better predictors for alcohol use. This is most likely a result of abundant theoretical basis for employee drinking problems. Job factors as a whole was not a significant predictor for number of drinks per occasion, suggesting there may be a threshold effect of job on the number of drinks. Marijuana use was the least effectively predicted and could be the result of the vigorous control for individual differences in the current study. It also suggested a lack of understanding of employee marijuana use. Other illicit drug use was not as well predicted as alcohol use, but had the best model fit, indicating some unobserved interaction terms should be added into the model.

Another major contribution of the current study concerns self-selection. It was argued that the prevalence of substance use in the food service industry may be explained by a self-selection hypothesis (Larsen, 1994). In other words, people who are predisposed to work for the food service industry are those who are likely to be alcohol or drug users in the first place. While rarely used in workplace literature, selection bias is common in economics and adolescent substance use research. For example, Bachman, Safron, Sy and Schulenberg (2003) found that desired working hours among youth were linked to their substance use. This current thesis is one of the earliest attempts to investigate self-selection effect for substance use in the food service industry.

Using a multinomial logistic regression model and controlling for previous and present employment, the current research found that binge drinking and marijuana use predicted employment in the food service industry. An addition day (within a month) engaged in binge drinking increased the odds by 5.37 percent; and an addition day 
engaged in marijuana use increased the odds by 1.41 percent, suggesting an moderate effect of self-selection among binge drinkers and marijuana users. Days of alcohol use, however, had a negative self-selection effect on employment in the food service industry, although the effect was marginally significant. One can argue that days of alcohol use by itself does not suggest any problem use of alcohol. Drinking moderately is considered normative among mature adults. Binge and heavy drinking, instead, was a major problem for food service industry employees (Larson et al., 2007). Therefore, selfselection among binge alcohol users posed a greater concern.

The existence of self-selection effect suggests that some features of the industry may "attract" these individuals. For example, the food service industry is not very selective on job candidates and thus is more likely to "absorb" the substance users. Consequently, self-selection may contribute to permissive substance use norms, which means higher approval of substance use by supervisors and coworkers. The approval of use, or permissive norms, can be explained by two reasons. First, the supervisors and managers in the food service industry may also be heavier alcohol uers or current illicit drug users, thus approving subordinate's use. Second, food service supervisors or managers may believe that a more selective hiring method, such as a drug tests, would exclude too many candidates from their hiring pool.

Support on self-selection hypothesis has several indications for future research. First, the current study demonstrated a self-selection effect in the food service industry, suggesting the permissive norms can be partially explained by employee self-selection. Future studies on other high use industry can also examine the self-selection effect. Next, 
the evidence of self-selection provides an explanation for the weak findings in the past workplace literature. Many argued substance use was a function of individual differences, rather than a function of workplace factors (e.g.: Harris, 2004; Harris \& Heft, 1992; Herold \& Conlon, 1981; Hogan et al., 2003; Lehman et al., 1995; Newcomb, 1994). Results from this study suggested that substance users could be attracted to certain workplaces. Norms may be the intermediate component, which attract substance users and are reinforced by incoming users. It is for future research to develop a comprehensive model to integrate individual qualities together with workplace norms using self-selection effect. Moreover, the self-selection effect could be stronger among older food service employees. Since the motivation of working in the food service industry can be very different for the older ones compared to the college-age inviduals, future research can test self-selection using a sample of older employees.

Using tenure in the food service industry as a proxy for one's cumulative exposure to a strong permissive norm, the current study found no evidence to support the hypothesis, which posits substance use norms in the food service industry would cultivate employee substance use. Not only the explanatory variable was non-significant across all models, the effect sizes were negligible, suggesting tenure failed to predict substance use entirely. This result, however, may be explained by three reasons. First and foremost, the relationship between cumulative exposure and employee substance use may be nonlinear, i.e., the effect of exposure may act within a short period then disappear. For example, one month working in the food service industry may be long enough to get one accustomed to heavy drinking or use illicit drug. After that, one will either continue to 
abstain or become a substance user. Besides non-linearity, the limited age group in the current sample may have restricted the range of tenure (average tenure in the food service industry was only 1.84 years) and thus failed to capture the true effect of exposure to the strong norms. Another possible explanation is that the effect of cumulative exposure on substance use may act through other job predictors, such as occupational differences and tip earning. Since the current study controlled for these factors, the effect of cumulative exposure was attenuated. Given these said, future research can take a closer examination of the link between tenure and substance use, using an older sample. If the non-linearity exists, future study can identify the threshold of the 'period of socialization' for newly employed workers in terms of alcohol or drug use.

Another hypothesis failed to be supported is the norm for socializing. It was hypothesized that individuals who worked an evening shift would engage in more substance use. Contrarily, results showed evidence against the hypothesis and the shift variables mostly had a negative effect on alcohol or illicit drug use, suggesting the reference group (mainly composed of regular day shift) may be associated with more substance use. There are three possible explanations for the interesting results. First of all, since evening is the part of the day when it is socially acceptable to drink, those work an evening shift may have less free time for recreational drinking as compared to those work non-evening shifts. Moreover, as the current sample was composed of college-aged individuals, those worked an evening shift may be engaged in school activities during the day, whereas those work a day shift may not. Since school enrollment is an indicator of academic achievement, which has been documented as a predictor of substance use (e.g.: 
Bachman, Johnston, \& O'Malley, 1981; Bryant, Schulenberg, O'Malley, Bachman, \& Johnston, 2003; Hawkins et al., 1994; Schulenberg et al., 1994; Kogan, Luo, Brody, \& Murry, 2005), work shifts can be confounded with academic achievement in explaining substance use, at least among a college-age sample. Another possible explanation would be there is an interaction between shifts and types of food service establishment, or between shifts and tip earning. Future study can test if an interaction term containing evening shift has a positive impact on food service employees' substance use.

To summarize the major findings, the current thesis attempts to explain prevalent substance use in the food service industry via two approaches: self-selection and jobrelated risk factors. The self-selection effect was supported with moderate evidence, suggesting binge drinkers and marijuana users were more likely to work in the food service industry. Several risk factors specific to this industry have been identified. Bartenders were found to be engaged in more days of alcohol use, alcohol binge use and other illicit drug use than the other food service occupations. Holding multiple jobs is another risk factor to alcohol or other illicit drug use. Tip earnings were found to increase alcohol use, particularly number of drinks consumed. However, tenure in the industry or working an evening shift failed to show any association with employee substance use. Moreover, alcohol use was the best predicted substance use outcome given the current risk factors. Marijuana use was found to be the least relevant outcome for the study. Further understanding on marijuana and other illicit drug use is warranted to fill in the knowledge gap.

Aside from the above findings, perhaps the most important contribution of the 
current study is its research design and implication for future research. Using national panel data containing substance use and employment history, the current analysis largely controlled for any non-job-related personal propensity to substance use. Although several reviews have consented that substance use was largely a function of individual disposition rather than workplace factors (Newcomb, 1994; Lehman et al., 1995; Harris, 2004; Hogan et al., 2003), the current thesis demonstrates that after controlling for an array of individual characteristics as well as previous use, employee substance use (especially alcohol use) continued to be a function of job-related risk factors among a group of young food service employees. Furthermore, the three major risk factors identified by the current study, i.e., alcohol serving, earning tips, holding multiple jobs, have an overall effect size no smaller than previous substance use. Therefore, attributing employee substance use to non-job-related individual factors should not be viewed appropriate globally. At certain work environment where there is a strong substance use

norm, employee substance use can be largely dependent on job risk factors. Researchers thus should continue to examine the impact of workplace on employee's substance use.

\section{Implications}

Two major strategies have been used to handle the problem of employee substance use: employee assistance program (EAP) and drug testing. EAP attempts to identify troubled employees and provide them with appropriate treatment services (Cook, Hersch, Back, \& McPherson, 2004). It has been shown that EAPs are generally effective in helping alcoholic employees and raising awareness of risks problem drinking (Roman 
\& Blum, 1996; Roman \& Blum, 2002; Sonnenstuhl, 1996). The other common strategy is drug testing, which is ultimately designed to remove illicit drug users from workforce (Cook et al., 2004). Drug testing is widely adopted by companies for its presumed impact on safety, productivity and employer costs (Cook \& Schlenger, 2002). However, there has been a lack of scientific evidence to determine the actual effect of drug testing (Normand, Lempert, \& O'Brien, 1994; Trice \& Steele, 1995). Although EAP and drug testing have gained growing recognition, both strategies are not targeted at mainstream employees to prevent substance use or alter beliefs about substance use (Cook et al., 2004; Cook \& Schlenger, 2002).

In addition to EAP and drug testing, various programs aiming at substance use prevention were developed. Particularly, programs such as peer assistance and work group training emphasize on a drug-free workplace norm; there are also programs such as stress management and worker health counseling which focus at promoting health awareness to individual employees (Cook \& Schlenger, 2002; Roman \& Blum, 2002). These programs are gaining accelerating attention, however, their benefits are hard to test.

Implementing prevention programs in the food service industry poses additional challenges. As the industry typically is consisted of small private operators running a very slim profit margin (James, James, \& Baldwin, 2003; Pratt, 2005), it is not feasible for the businesses to establish a formal substance use prevention program. Therefore, informal programs that target at job-related risk factors are more practical to implement for most food service operators. 
Based on the findings from the current study, three prevention strategies are formulated for food service practitioners. First, to combat with the prevalent substance use problem, managers should start by minimizing the self-selection effect. Since current marijuana users were shown to be more likely to choose to work in the food service industry, deploying drug tests can rule out these individuals. Regarding alcohol users' self-selection, the current results showed binge or heavy alcohol users were more likely to be "attracted" to the industry. However, because current alcoholism is protected by the Americans with Disabilities Act, food service employers cannot discriminate these applicants. A proper resolution would be emphasizing a strict alcohol-free policy during the interviews to ward off those binge and heavy drinkers.

Furthermore, substance use prevention program should be framed in terms of workplace risk factors (Bennett, Lehman, \& Reynolds, 2000). Since tips were found to facilitate the consumption of alcohol or illicit drugs and tips are usually paid to employees in cash at the end of the day, implications for both managers and employees center on money management. If possible, managers may consider paying tips via standard payment methods, e.g., direct deposit, check. On the same note, changing payment period from end of shift to weekly may reduce spending impulse. For the employees, especially the younger ones, education is needed on money management. Managers can play an active role by informally mentioning this during shift briefings.

Last but not least, the key to prevent employee substance use in the food service industry is an overarching culture promoting healthy work environment. Food service establishments are recommended to implement a drug-free workplace policy (SAMHSA, 
n.d.). An effective policy should define substance use, set expectations and state the prohibitions; and the policy should be written and enforced throughout the organization. All employees including bartenders are expected to follow the policy. Consequently, implicit consents on bartender alcohol use at work should be eliminated.

To compliment and reinforce a drug-free policy, food service establishments can implement a team-oriented health promotion program (Bennett, Lehman, \& Reynolds, 2000; Cook, Back, \& Trudeau, 1996a, 1996b: Cook, Back, Trudeau, \& McPherson, 2002). General health awareness topics, such as stress management or consequences of substance use, can be discussed among all the employees. Managers are also recommended to encourage collaborations among the employees. As a health promotion program increases the level of knowledge about the risk of substance use, teamwork can enhance effectiveness of workplace policy and improves group supervision (Bennett \& Lehman, 1998; Bennett et al., 2000; Ames et al., 2000; Roman \& Blum, 2002).

\section{Limitations}

Two methodological limitations may restrict the conclusiveness of the current thesis. One limitation arises from the conditions imposed on the sample. The narrow age range constrains the scope of the current thesis to individuals between 18 and 23 years of age. However, half of food service employees are over 25 years of age. Thus, the results of this study should not be extrapolated to older groups. In addition, the current sample consists of working individuals only, thus results are not relevant to non-working individuals' substance use. This is particularly true for minorities. In this study, African 
American group had significant negative coefficients for drinking, marijuana, and illicit drugs. Johnson (2004) posits this is true for African Americans who are currently employed, but not for African Americans overall.

The other limitation is the limited workplace variables in the NLSY97 questionnaire. Direct measurements on employee stress, workplace norms, alcohol or drug availability, and workplace policies are not present in the data. Therefore, indirect measurements were used when testing availability, norm and stress theory. This hinders the study's ability to capture the actual effects as predicted by these theories.

\section{Future Directions}

The results from this research provide five aspects for future research directions. First, because the current study only investigated young people, whose motivation to work in the food service industry can be very different from the older ones, future research can test self-selection using a sample of older employees. Next, although the current study failed to support the cumulative exposure hypothesis, it raises a future research opportunity to examine the boundary of norm theory via identifying the threshold of 'period of socialization' for newly employed workers in terms of alcohol or drug use. Third, the current study provides a broad examination of job-related risk factors in the food service industry. Future study can take a closer examination at employees' behavioral or psychological factors (e.g., job satisfaction, supervisor support, coping behavior) as indicators of substance use. For example, further understanding is needed on the patterns and reasons for alcohol use among bartenders and servers. Fourth, 
as a variety of substance use outcomes was examined in the current research, results suggested the theoretical framework for alcohol use was relatively developed but and the understanding for illicit drug use, at least among workers, remained insufficient. Future research attention is therefore warranted for a comprehensive investigation of employee illicit drug use. Last but not least, the effectiveness of prevention or intervention programs has never been tested in the food service industry, thus raises opportunities for future research. A multi-stage program can be experimented within food service organizations: first the pattern and motivation of employee substance use need to be assessed; then various interventions such as withholding tip earnings for the employees, implementing a drug-free policy, or delivering a health education program.

\section{Conclusion}

Employee substance use is a sophisticated behavioral problem resulted from complicated internal and external factors. The food service industry is chosen as the focus for this study because this industry has been having a large proportion of employees with heavy drinking and drug using problems. The current study tested selfselection and examined several job-related risk factors among a group of college-aged individuals. Results showed some evidence to the self-selection hypothesis, indicating previous binge alcohol use and marijuana use increased an individual's propensity to be employed in the food service industry. After controlling for previous use and other individual variability, several job risk factors specific to the food service industry have been identified. Specifically it was found that bartending, holding multiple jobs, and tip 
earning were the three strongest risk factors. Implications for food service managers and employees include money management, health promotion program and implementation of drug-free workplace policy. Future research opportunities involve conceptual and methodological improvement on the current thesis. 


\section{APPENDIX A \\ DESCRIPTIVE STATISTICS OF THE SELF-SELECTION SAMPLE BREAK-DOWN BY FOOD SERVICE, OTHER HIGH-USE, AND LOW-USE INDUSTRIESS}




\begin{tabular}{|c|c|c|c|}
\hline Variable (2001) & $\begin{array}{l}\text { Food Service } \\
\qquad(\mathrm{n}=775)\end{array}$ & $\begin{array}{l}\text { Other High Use } \\
\text { Industries } \\
(\mathrm{n}=278)\end{array}$ & $\begin{array}{l}\text { Low Use } \\
\text { Industries } \\
(\mathrm{n}=3651)\end{array}$ \\
\hline Age & $18.77(1.39)$ & $19.16(2.05)$ & $19.14(1.40)$ \\
\hline Male & 0.45 & 0.92 & 0.48 \\
\hline White & 0.56 & 0.68 & 0.50 \\
\hline Asian/Pacific Islander & 0.02 & 0.01 & 0.02 \\
\hline African American & 0.21 & 0.09 & 0.23 \\
\hline Hispanic/ Latino & 0.10 & 0.10 & 0.12 \\
\hline Native American & 0.01 & 0.01 & 0.01 \\
\hline Other & 0.04 & 0.03 & 0.05 \\
\hline Married & 0.06 & 0.08 & 0.07 \\
\hline Highest grade completed & $11.59(1.43)$ & $11.28(1.36)$ & $12.00(1.95)$ \\
\hline Peer alcohol use & $2.03(1.18)$ & $2.18(1.23)$ & $2.17(1.23)$ \\
\hline Peer drug use & $2.28(1.29)$ & $2.42(1.37)$ & $2.29(1.27)$ \\
\hline Income (\$1000) & $30.45(44.86)$ & $33.08(46.00)$ & $37.05(50.64)$ \\
\hline Days of alcohol use & $3.69(5.97)$ & $5.17(7.41)$ & $3.36(5.56)$ \\
\hline Days of binge alcohol use & $1.91(4.28)$ & $2.58(5.13)$ & $1.49(3.63)$ \\
\hline No. alcohol per day & $3.06(5.70)$ & $3.95(5.79)$ & $2.81(6.00)$ \\
\hline Days use marijuana & $3.20(7.89)$ & $3.91(9.40)$ & $2.06(6.50)$ \\
\hline Times other illicit drug use & $3.23(26.69)$ & $5.09(29.29)$ & $1.64(17.32)$ \\
\hline Total jobs & $1.66(1.03)$ & $1.76(1.09)$ & $1.66(1.06)$ \\
\hline Tenure in this ind. & $0.82(0.75)$ & $0.94(1.18)$ & $1.32(1.49)$ \\
\hline
\end{tabular}

Note: Data is reported as mean(std) or proportions. 
APPENDIX B

MULTINOMIAL LOGISTIC REGRESSION RESULTS

FOR SELF-SELECTION INTO HIGHER USE INDUSTRY 


\begin{tabular}{ll} 
& $\begin{array}{c}\text { Logit } \\
\text { Coefficients }\end{array}$ \\
\hline Intercept & -0.79 \\
Days use alcohol & 0.01 \\
Days binge use alcohol & 0.00 \\
No. drinks per day & -0.00 \\
Days use marijuana & 0.01 \\
Times use other illicit drug & 0.00 \\
Age & -0.03 \\
Male & $1.78^{* * *}$ \\
Asian / Pacific Islander & -0.48 \\
African American & $-0.72^{* * *}$ \\
Latino / Hispanic & -0.25 \\
Native American & 0.31 \\
Other race & $-0.67^{*}$ \\
Married & 0.20 \\
Highest grade completed & $-0.27^{* * *}$ \\
Peer alcohol use & -0.08 \\
Peer drug use & $0.16^{* *}$ \\
Income (\$1000) & $.00^{* *}$ \\
Previously work in this ind. & $2.24^{* * *}$ \\
Previous tenure in this ind. & $0.92^{* * *}$ \\
Previous tenure in lower use ind. & $0.13^{* *}$ \\
Total jobs in previous year & $-0.21^{* * *}$ \\
&
\end{tabular}

Note: p-values reflect one-tailed test.

$$
\begin{aligned}
& \mathrm{p}<.1 * \\
& \mathrm{p}<.05 * * \\
& \mathrm{p}<.01 * * *
\end{aligned}
$$




\section{APPENDIX C}

F-TESTS FOR OVERALL SIGNIFICANT

OF THE JOB-RELATED RISK FACTORS 


\begin{tabular}{lll} 
& F-statistic & p-value \\
\hline Days use alcohol*** & 2.600 & .00418 \\
Days binge use alcohol ** & 1.879 & .04487 \\
No. of drinks & 0.888 & .54403 \\
Days use marijuana & 0.630 & .78883 \\
Times use other illicit drug* & 1.842 & .05024
\end{tabular}




\section{REFERENCES}

Akers, R.L. (1977). Deviant behavior: A social learning approach. Belmont, CA: Wadsworth.

Ames, G.M., \& Grube, J.W. (1999). Alcohol availability and workplace drinking: Mixed method analyses. Journal of Studies on Alcohol, 60(3), 383-393.

Ames, G.M., Grube, J.W., \& Moore, R.S. (2000). Social control and workplace drinking norms: A comparison of two organizational culture. Journal of Studies on Alcohol, 61(2), 203-219.

Anthony, J.C., \& Arria, A.M.(1999). Epidemiology of substance abuse in adulthood. In M.R., Frone (Ed.). Predictors of overall and on-the-job substance use among young workers. Journal of Occupational Health Psychology, 8(1), 39-54.

Anthony, J.C., \& Helzer, J.E. (1995). Epidemiology of drug dependence. In K.L. Davis, D. Charney, J.T. Coyle, \& C. Nemeroff (Eds.). Neuropsychopharmacology: The fifth generation of progress (pp. 1558-1560).

Apel, R., Paternoster, R., Bushway, S., \& Brame, R. (2006). A job isn't just a job: The differential impact of formal versus informal work on adolescent problem behavior. Crime \& Delinquency, 52(2), 333-369.

Auerswald, E.H. (1980). Drug use and families: In the context of twentieth century science. In B.G. Ellis (Ed.). Drug abuse from the family perspective: Coping is a family affair. Rockville, MD: National Institute on Drug Abuse. (ERIC Document Reproduction Service No. ED205849)

Bachman, J.G., Safron, D.J., Sy, S.R., \& Schulenberg, J.E. (2003). Wishing to work: new perspectives on how adolescents' part-time work intensity is linked to educational disengagement, substance use, and other problem behaviors. International Journal of Behavioral Development, 27(4), 301-315.

Bachman, J.G., Johnston, L.D., \& O'Malley, P.M. (1981). Smoking, drinking, and drug use among American high school students 1975-1979: Correlates and trends. American Journal of Public Health, 71(1), 59-69. 
Bacharach, S.B., Bamberger, P.A., \& Sonnenstuhl, W.J. (2002). Driven to drink: Managerial control, work-related risk factors, and employee problem drinking. Academy of Management Journal, 45(4), 637-658.

Bandura, A. (1973). Aggression: A social learning analysis. Englewood Cliffs, NJ: Prentice-Hall.

Bandura, A. (1977). Self-efficacy: Toward a unifying theory of behavioral change. Psychological Review, 84(2), 191-215.

Baker, D.B. (1985). The study of stress at work. Annual Review of Public Health, 6(May), 367-381.

Barling, J., Kelloway, E.K., \& Frone, M.R. (2004). Handbook of work stress (pp.13). Sage Publications Inc.

Barnes, G.M. (1977). The development of adolescent drinking behavior: An evaluative review of the impact of the socialization process within the family. Adolescence, 12(48), 571-590.

Barnett, R.C., \& Baruch, G.K. (1985). Women's involvement in multiple roles and psychological distress. Journal of Personality and Social Psychology, 49(1), 135-145.

Beehr, T.A. (1985). Human stress and cognition in organizations. New York: John Wiley \& Sons.

Bennett, J.B., \& Lehman, W.E.K. (1998). Workplace drinking climate, stress, and problem indicators: Assessing the influence of teamwork (group cohesion). Journal of Studies on Alcohol, 59(5), 608-618.

Bennett, J.B., Lehman, W.E.K., \& Reynolds, G.S. (2000). Team awareness for workplace substance abuse prevention: The empirical and conceptual development of a training program. Prevention Science, 1(3), 157-173.

Bernstein, M., \& Mahoney, J.J. (1989). Management perspective on alcoholism: The employer's stake in alcoholism treatment. Occupational Medicine, 4(2), 223-232.

Brandeis University, MA, Institute for Health Policy. (2001). Substance Abuse: The nation's number one health problem. Princeton, NJ: The Robert Wood Johnson Foundation.

Bryant, A.L., Schulenberg, J.E., O'Malley, P.M., Bachman, J.G., \& Johnston, L.D. 
(2004). How academic achievement, attitudes, and behaviors relate to the course of substance use during adolescence: A 6-year, multiwave national longitudinal study. Journal of Research on Adolescence, 13(3), 361-397.

Boys, A., Farrell, M., Bebbington, P., Brugha, T., Coid, J., Jenkins, R., et al. (2002). Drug use and initiation in prison: Results from a national prison survey in England and Wales. Addiction, 97(12), 1551-1560.

Burden, D.S. (1986). Single parents and the work setting: The impact of multiple job and homelife responsibilities. Family Relations, 35(1), 37-43.

BLS, Bureau of Labor Statistics. (2007). Career guide to industries, 2008-09 Edition, Food services and drinking places. Retrieved June 28, 2008 from http://www.bls.gov/oco/cg/cgs023.htm

Carr, R.V. (1995). Effects of teenage work experience over ten years: Evidence from the National Longitudinal Survey of Youth. Dissertation Abstracts International. A 56(07), (UMI: 9538567)

Cahalan, D., \& Cisin, J.H. (1976). Drinking behavior and drinking problems in the U.S. In S. Stack \& I. Wasserman (1993). Marital status: alcohol consumption and suicide. Journal of marriage and the family, 55(4), 1018-1024.

Chaloupka, F.J., \& Wechsler, H. (2004). Binge drinking in college: The impact of price, availability, and alcohol control policies. Contemporary Economic Policy, 14(4), 112-124.

Clark, V. (2004). SAS/STAT 9.1 user's guide (pp.78, 79, 699). SAS Institute. SAS Publishing.

Coambs, R.B. \& McAndrews, M.P. (1994). The effects of psychoactive substances on workplace performance. In S. Macdonald \& P.M. Roman (Eds.), Research Advances in Alcohol and Drug Problems, Vol.11. Drug Testing in the Workplace. NY: Plenum Press.

Colder, C. R., \& Chassin, L. (1993). The stress and negative affect model of adolescent alcohol use and the moderating effects of behavioral undercontrol. Journal of Studies on Alcohol, 54(3), 326-333.

Conway, T.L., Vickers, R.R., Ward, H.W., \& Rahe, R.H. (1981). Occupational stress and variation in cigarette, coffee, and alcohol consumption. Journal of Health and Social Behavior, 22(2), 155-165.

Cook, R.F., Back, A.S., \& Trudeau, J.V. (1996a). Substance abuse prevention in the 
workplace: Recent findings and an expanded conceptual model. The Journal of Primary Prevention, 16(3), 319-338.

Cook, R.F., Back, A.S., \& Trudeau, J.V. (1996b). Preventing alcohol use problems among blue-collar workers: A field test of the working people program. Substance Use and Misuse, 31(3), 255-275.

Cook, R.F., Back, A.S., Trudeau, J.V., \& McPherson, T.L. (2002). Integrating substance abuse prevention into health promotion programs in the workplace. In J. Bennett \& W. Lehman (Eds.), Preventing workplace substance abuse: Beyond drug testing to wellness. Washington, DC: American Psychological Association.

Cook, R.F., Hersch, R.K., Back, A.S., \& McPherson, T.L. (2004). The prevention of substance abuse among construction workers: A field test of a social-cognitive program. The Journal of Primary Prevention, 25(3), 338-350.

Cook, R.S., \& Schlenger, W. (2002). Prevention of substance abuse in the workplace: Review of research on the delivery of services. The Journal of Primary Prevention, 23(1), 115-143.

Cooper, M.L, Russell, M., \& Frone, M.R. (1990). Work stress and alcohol effects: A test of stress-induced drinking. Journal of Health and Social Behavior, 31(3), $260-276$.

Corsun, L.D., \& Young, C.A. (1998). An occupational hazard: Alcohol consumption among hospitality managers. Marriage \& Family Review, 28(1-2), 187-211.

Deaton, A.S. (1992). Understanding Consumption. Oxford University Press, New York.

DiNardo, J. (1994). A critical review of the estimates of the costs of alcohol and drug use. In S. Macdonald \& P.M. Roman (Eds.), Research Advances in Alcohol and Drug Problems, 11: Drug testing in the workplace (pp.57-74). Plenum Press, NY.

Elliott, D.S., Huizinga, D., \& Ageton, S.S. (1982). Explaining delinquency and drug use (Report No. NCJ 128886). Boulder, CO: Behavioral Research Institute.

Fair Labor Standard Acts. (2008). Youth employment. Retrieved on August 19, 2008, from: http://www.dol.gov/esa/whd/childlabor.htm

Fontana, D. (1989). Managing stress. Leicester: British Psychological Society.

Foster, B. (1984). Upper middle class adolescents' drug use: Patterns and factors. Advances in Alcohol and Substance Abuse, 4(2), 27-36. 
French, J.R.P., \& Caplan, R.D. (1973). The failure of success. New York: AMACOM.

Frone, M.R. (1999). Work stress and alcohol use. Alcohol Research \& Health, 23(4), 284-291.

Frone, M.R. (2003). Predictors of overall and on-the-job substance use among youth workers. Journal of Occupational Health Psychology, 8(1), 39-54.

Fudenberg, D. \& Levine, D.K. (2006). A dual-self model of impulse control. American Economic Review, 96(5), 1449.

Ghodse, A.H. (1995). Drugs and addictive behaviors: A guide to treatment (2nd ed.). Oxford: Blackwell Science.

Goode, W.J. (1960). A theory of strain. American Sociological Review, 25(4), 483-496.

Goodman, E., \& Huang, B. (2002). Socioeconomic status, depressive symptoms, and adolescent substance use. Archives of Pediatrics and Adolescent Medicine, $156(5), 448-453$.

Greenberg, E., \& Grunberg, L. (1995). Work alienation and problem alcohol behavior. Journal of Health and Social Behavior, 36(1), 83-102.

Hammer, T.H., Saksvik, P.O., Nytroe, K., Torvatn, H., \& Bayazit, M. (2004). Expanding the psychosocial work environment: Workplace norms and work-family conflict as correlates of stress and health. Journal of Occupational Health Psychology, 9(1), 83-97.

Hanson, D.J. (2005). Minimum age to serve alcoholic beverage in on-premises establishments. Retrieved June 28, 2008 from http://www2.potsdam.edu/hansondj/StateAndLocalLaws/1133835601.html

Harris, M.M. (2004). Alcohol and drug use in the workplace. In R.W. Griffin \& A.M. O’Leary-Kelly (Eds.), The Dark side of organizational behavior (pp.341-372). San Francisco: John Wiley \& Sons, Inc.

Harris, M.M., \& Heft, L. L. (1992). Alcohol and drug use in the workplace: Issues, controversies, and directions for future research. Journal of Management, 18(2), 239-266.

Hawkins, J.D., Catalano, R.F., \& Miller, J.Y. (1992). Risk and protective factors for alcohol use and other drug problems in adolescence and early adulthood: Implications for substance use prevention. Psychological Bulletin, 112(1), 64-105. 
Head, J., Stansfeld, S.A., \& Siegrist, J. (2004). The psychosocial work environment and alcohol dependence: A prospective study. Occupational and Environmental Medicine, 61(3), 219-224.

Heien, D., \& Pompelli, G. (1987). Stress, ethnic, and distribution factors in a dichotomous response model of alcohol abuse. Journal of Studies on Alcohol, $48(5), 450-455$.

Hermos, J.A., Winter, M.R., \& Heeren, T.C. (2008). Early age-of-onset drinking predicts prescription drug misuse among teenages and young adults: Results from a national survey. Journal of Addiction Medicine, 2(1), 22-30.

Herold, D. M., \& Conlon, E.J. (1981). Work Factors as Potential Causal Agents of Alcohol Abuse. Journal of Drug Issues, 11(3), 337-56.

Hoffman, J.P., Brittingham, A., \& Larison, C. (1996). Drug use among U.S. workers: Prevalence and trends by occupation and industry categories (pp.73). DIANE Publishing.

Hogan, J.A., Gabrielsen, K.R., Luna, N., \& Grothaus, D. (2003). The Risk and protective factors theory. The Intersection of Science and Practice: Substance Abuse Prevention. Boston, MA: Pearson Education, Inc.

Huffman, D., \& Barenstein, M. (2005). A monthly struggle for self-control? Hyperbolic discounting, mental accounting, and the fall in consumption between paydays. IZA organization discussion papers. Retrieved June 29, 2008 from http://ftp.iza.org/dp1430_rev.pdf

International Center for Alcohol Policies. (2003, August). Alcohol and the Workplace (pp.5), (No.13). Washington, DC.

James, J., James, J.R., \& Baldwin, D. (2003). Restaurant management: a comprehensive guide to successfully owning and running a restaurant (pp.304). Adams Media, MA: Avon.

Jessor, R., Chase, J.A., \& Donovan, J.E. (1980). Psychosocial correlates of marijuana use and problem drinking in a national sample of adolescents. American Journal of Public Health, 70(6), 604-613.

Johnson, M.K. (2004). Further Evidence on Adolescent Employment and Substance Use: Differences by Race and Ethnicity. Journal of Health and Social Behavior, 45(2), 187-197. 
Kandel, D.B., Kessler, R.C., \& Margolies, R. (1978). Longitudinal research on drug use. New York: John Wiley and Sons.

Kogan, S.M., Luo, Z., Murry, V.M., \& Brody, G.H. (2005). Risk and protective factors for substance use among African high school dropouts. Psychology of Addictive Behaviors. Journal of Ethinicity in Substance Abuse, 4(1), 35-51.

Kuper, H., \& Marmot, M. (2003). Job strain, job demands, decision latitude, and risk of coronary heart disease within the Whitehall II study. Journal of Epidemiology and Community Health, 57(2), 147-153.

Larsen, S. (1994). Alcohol use in the service industry. Addiction, 86(6), 733-741.

Larson, S.L., Eyerman, J., Foster, M.S. \& Gfroerer, J.C. (2007). Work substance use and workplace policites and programs (DHHS Publication No. SMA 07-4273, Analytic Series A-29). Rockville, MD: Substance Abuse and Mental Health Services Administration, Office of Applied Studies.

Lehman, W.E.K., \& Bennett, J. (2002). Job risk and employee substance use: The influence of personal background and work environment factors. The American Journal of Drug and Alcohol Abuse, 28(2), 263-286.

Lehman, W.E.K., Farabee, D.J., Holcom, M.L., \& Simpson, D. (1995). Prediction of substance use in the workplace: Unique contributions of personal background and work environment variables. Journal of Drug Issues, 25(2), 253-274.

Lehman, W.E.K., \& Simpson, D.D. (1992). Employee substance use and on-the-job behaviors. Journal of Applied Psychology, 77(3), 309-321.

Linsky, A.S., Straus, M.A., \& Colby, J. (1985). Stressful events, stressful conditions, and alcohol problems. Journal of Studies on Alcohol, 46(1), 72-80.

Lu, J.L. (2008). Organizational role stress indices affecting burnout among nurses. Journal of International Women's Studies, 9(3), 63-78.

Lynn, W. M. (2006). Tipping in restaurants and around the globe: An interdisciplinary review. In M. Altman (Ed.), Handbook of contemporary behavioral economics: Foundations and developments. Available at SSRN: $\mathrm{http}: / /$ ssrn.com/abstract= 465942

MacDonald, S., Well, S., \& Wild, T.C. (1999). Occupational risk factors associated with alcohol and drug problems. American Journal of Drug and Alcohol Abuse, 25(2), 351-369. 
Maddahian, E., Newcomb, M.D., \& Bentler, P.M. (1986). Adolescents' substance use: Impact of ethnicity, income and availability. In B. Stimmerl (Ed.), Alcohol and Substance Abuse in Women and Children (pp.63-78). The Haworth Press, Inc.

Mannello, T.A., \& Seaman, F.J. (1979). Prevalence, costs and handling of drinking problems on seven railroads. Final report, Washington, DC, University Research Corporation. In S.B. Bacharach, P.A. Bamberger \& W.J. Sonnenstuhl (Eds.), Driven to drink: Managerial control, work-related risk factors, and employee problem drinking, Academy of Management Journal, 45(4), 637-658.

Marlatt, G.A. (1985). Relapes prevention: Theoretical rationale and overview of the model. In G.A. Marlatt \& J.R. Gordon (Eds.), Relapse prevention: Maintenance strategies in the treatment of addictive behaviors (pp.5). New York: Guilford.

Mensch, B.S., \& Kandel, D.B. (1988). Do job conditions influence the use of drugs? Journal of Health and Social Behavior, 29(2), 169-184.

Morris, R.T. (1956). A typology of norms. American sociological review, 23(5), 610-613.

Muhammad, J., Baba, V.V., \& Riviere, R. (1998). Job stress and well-being of moonlighters: The perspective of deprivation or aspiration revisited. Stress Medicine, 14(3), 195-202.

National Criminal Justice Reference Service, (1997). The National drug control strategy, 1997. (Office of National Drug Control Policy, NCJ 163915). Rockville, MD.

NLS, The National Longitudinal Surveys. (2007). NLSY97 user's guide: A guide to the rounds 1-9 data national longitudinal survey of youth 1997. Retrieved on August 19, 2008 from: http://www.nlsinfo.org/nlsy97/docs/97HTML00/97guide/toc.htm

Newcomb, M.D. (1994). Prevalence of alcohol and other drug use on the job: Cause for concern or irrational hysteria. Journal of Drug Issues, 24(3), 403-416.

Norman, J., Lempert, R.O., \& O'Brien, C.P. (Eds.) (1994). Under the influences? Drugs and the American work force. National Research Council/Institute of Medicine. Washington, DC: National Academy Press.

O’Malley, P.M., Johnston, L.D., \& Bachman, J.G. (1999). Epidemiology of substance abuse in adolescence. In M.R. Frone (Ed.), Predictors of overall and on-the-job substance use among young workers. Journal of Occupational Health Psychology, 8(1), 39-54.

Paglia, A., \& Room, R. (1999). Preventing substance use problems among youth: A 
literature review and recommendations. The Journal of Primary Prevention, 20(1), 3-50.

Parker, D.A., \& Brody, J.A. (1982). Risk factors for alcoholism and alcohol problems among employed women and men. In B.S. Mensch \& D.B. Kandel (Eds), Do job conditions influence the use of drugs? Journal of Health and Social Behavior, 29(2), 169-184.

Paternoster, R., Brame, R., Mazerolle, P., \& Piquero, A. (2006). Using the correct statistical test for the equality of regression coefficients. Criminology, 36(4), $859-866$.

Paternoster, R., Bushway, S., Brame, \& R., Apel, R. (2003). The effect of teenage employment on delinquency and problem behavior, Social Forces, 82(1), 297-335.

Peters, B.L. (2002). Alcohol consumption and productivity. Dissertation Abstracts International, A 63(09), (UMI No. 3066067).

Petraitis, J., Flay, B.R., \& Miller, T.Q. (1995). Reviewing theories of adolescent substance use: Organizing pieces in the puzzles. Psychological Bulletin, 117(1), $67-86$.

Plant, M.A. (1977). Alcoholism and occupation: A review. British Journal of Addiction, 72(4), 309-316.

Pratt, S.P. (2005). The market approach to valuing businesses (pp.100). John Wiley \& Sons, Inc., NJ: Hoboken.

Ramchand, R. (2006). Clocking out: Adolescent work experiences and drug involvement in an urban environment. Dissertation Abstracts International, B 67(04), (UMI No.: 3213788).

Roman, P.M., \& Blum, T.C. (1996). Alcohol: A review of the impact of worksite interventions on health and behavioral outcomes. American Journal of Health Promotion, 11(2), 136-149.

Roman, P.M., \& Blum, T.C. (2002). The workplace and alcohol problem prevention. Alcohol Research and Health, 26(1), 49-57.

Rosen, M.I., Bailey, M., \& Rosenheck, R.R. (2003). Alcohol \& drug abuse: Principles of money management as a therapy for addiction. Psychiatric Services, 54(2), $171-173$. 
Safron, D., Schulenberg, J., \& Bachman, J. (2001). Part-time work and hurried adolescence: The links among work intensity, social activities, health behaviors and substance use. Journal of Health \& Social Behavior, 42(4), 425-451.

SAMHSA. (n.d.) Drug-free workplace kit. Retrieved August 7, 2008 from http://www.drugfreeworkplace.gov/WPWorkit/policy.html

SAMHSA. (2007). Results from the 2006 national survey on drug use and health: national findings (Office of Applied Studies, NSDUH Series H-32, DHHS Publication No. SMA 07-4293). Rockville, MD.

SAMHSA. (2008a). Making your workplace drug free: a kit for employers. Retrieved April 16, 2008, from http://ncadi.samhsa.gov/govpubs/workit/folder.aspx

SAMHSA. (2008b). Results from the 2005 National Survey on Drug Use and Health: National Findings (NSDUH Series H-34, DHHS Publication No. SMA 08-4343). Rockville, MD.

Saunders, J.B. \& Aasland, O.G. (1987). WHO collaborative project on identification and treatment of persons with harmful alcohol consumption. Report on phase 1 (Geneva, World Health Organization). In S. Larsen (Ed.), Alcohol use in the service industry, Addiction, 86(6), 733-741.

Schneider, B. (1987). The people make the place. Personnel Psychology, 40(3), 437-453.

Schulenberg, J., Bachman, J.G., O'Malley, P.M., \& Johnston, L.D. (1994). High school educational success and subsequent substance use: A panel analysis following adolescents into young adulthood. Journal of Health and Social Behavior, 35(1), 45-62.

Shaner, A., Eckman, T., Roberts, L., Wilkins, J.N., Tucker, D.E., Tsuang, J.W. et al. (1995). Disability income, cocaine use, and repeated hospitalization among schizophrenic cocaine abusers: A government-sponsored revolving door? The New England Journal of Medicine, 333(12), 777-783.

Shilts, L. (1991). The relationship of early adolescent substance use to extracurricular activities, peer influence, and personal attitudes. Adolescence, 26(103), 613-618.

Sinha, R. (2001). How does stress increase risk of drug abuse and relapse? Psychopharmacology, 158(4), 343-359.

Smart, RG. (1980). An availability-proneness theory of illicit drug abuse. NIDA Research Monograph Series, 30(Mar), 46-49. 
Sonnenstuhl, W.J. (1996). Working sober. Ithaca, NY: Cornell University Press. In S.B. Bacharach, P.A. Bamberger \& W.J. Sonnenstuhl (Eds.), Driven to drink: Managerial control, work-related risk factors, and employee problem drinking. Academy of Management Journal, 45(4), 637-658.

Spooner, C. (1999). Causes and correlates of adolescent drug abuse and implications for treatment. Drug and Alcohol Review, 18(4), 453-475.

Stacy, A.W., Newcomb, M.D., \& Bentler, P.M. (1992). Interactive and higher-order effects of social influences on drug use. Journal of Health and Social Behavior, 33(3), 226-241.

Stubbs, A.G.P. (2001). Learning to pour: An exploration into the socialization of the male night shift bartender. Masters Abstracts International, 40(06), (UMI No. 952529).

Suchman, E.A. (1967). Evaluative research: Principles and practice in public service and social action programs. New York: Russell Sage Foundation.

Szalay, L., Strohl, J., \& Doherty, K. (1999). Background and group membership: Factors affecting substance abuse, psychoenvironmental forces in substance abuse prevention (pp.113-132). New York: Kluwer Academic/Plenum Publishers.

Teichman, M., Barnea, Z., \& Ravav, G. (1989). Personality and substance use among adolescents: A longitudinal study. Addiction, 84(2), 181-190.

Trice, H. M., \& Roman, P.M. (1972). Spirits and Demons at Work: Alcohol and Other Drugs on the Job. Ithaca: Cornell University Press.

Trice, H.M., \& Steele, P.D. (1995). Impairment testing: Issues and conversion with employee assistance programs. Journal of Drug Issues, 25(2), 471-503.

Trinkoff, A.M., Storr, C.L., \& Wall, M.P. (1999). Prescription-type drug misuse and workplace access among nurses, Journal of Addictive Diseases, 18(1), 9-18.

Vohs, K.D. \& Faber, R.J. (2007). Spend resources: Self-regulatory resource availability affects impulse buying. Journal of Consumer Research, 33(4), 537.

Wallace, B.C. (1989). Psychological and environmental determinants of relapse in crack cocaine smokers. Journal of Substance Abuse Treatment, 6(2), 95-106.

Wertenbroch, K., Soman, D., \& Nunes, J. (2002). Debt aversion and self-control consumer self-management of liquidity constraints. Unpublished manuscript, INSEAD. 
Wiesner, M., Windle, M., \& Freeman, A. (2005). Work stress, substance use, and depression among young adult workers: An examination of main and moderator effect model. Journal of Occupational Health Psychology, 10(2), 83-96. 